\title{
25 Years of Time Series Forecasting
}

\author{
Jan G De Gooijer \\ Department of Quantitative Economics \\ University of Amsterdam, Roetersstraat 11, 1018 WB Amsterdam, The Netherlands \\ Telephone: +31-20-525-4244; Fax: +31-20-525-4349 \\ Email: j.g.degooijer@uva.nl
}

\section{Rob J Hyndman}

Department of Econometrics and Business Statistics,

Monash University, VIC 3800, Australia.

Telephone: +61-3-9905-2358; Fax: +61-3-9905-5474

Email: Rob.Hyndman@buseco.monash.edu

Revised: 6 January 2006 


\title{
25 Years of Time Series Forecasting
}

\begin{abstract}
We review the past 25 years of research into time series forecasting. In this silver jubilee issue, we naturally highlight results published in journals managed by the International Institute of Forecasters (Journal of Forecasting 1982-1985; International Journal of Forecasting 1985-2005). During this period, over one third of all papers published in these journals concerned time series forecasting. We also review highly influential works on time series forecasting that have been published elsewhere during this period. Enormous progress has been made in many areas, but we find that there are a large number of topics in need of further development. We conclude with comments on possible future research directions in this field.
\end{abstract}

Keywords: Accuracy measures; ARCH; ARIMA; Combining; Count data; Densities; Exponential smoothing; Kalman filter; Long memory; Multivariate; Neural nets; Nonlinearity; Prediction intervals; Regime-switching; Robustness; Seasonality; State space; Structural models; Transfer function; Univariate; VAR.

\begin{tabular}{lll}
\hline & Introduction & 1
\end{tabular}

$\begin{array}{lll}2 & \text { Exponential smoothing } & 2\end{array}$

3 ARIMA 5

$\begin{array}{lll}4 & \text { Seasonality } & 10\end{array}$

5 State space and structural models and the Kalman filter 11

$\begin{array}{lll}6 \text { Nonlinear } & 13\end{array}$

$\begin{array}{lll}7 & \text { Long memory } & 17\end{array}$

\begin{tabular}{lll}
\hline & ARCH/GARCH & 18
\end{tabular}

$\begin{array}{lll}9 & \text { Count data forecasting } & 20\end{array}$

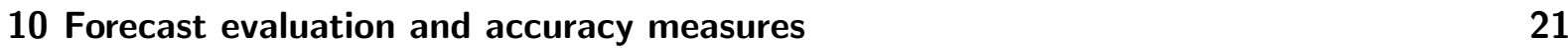

\begin{tabular}{ll}
\hline 11 Combining & 23
\end{tabular}

12 Prediction intervals and densities $\quad 24$

13 A look to the future $\quad 25$

\begin{tabular}{lr}
\hline Acknowledgments & 28
\end{tabular}

$\begin{array}{ll}\text { References } & 29\end{array}$ 


\section{Introduction}

The International Institute of Forecasters (IIF) was established 25 years ago and its silver jubilee provides an opportunity to review progress on time series forecasting. We highlight research published in journals sponsored by the Institute, although we also cover key publications in other journals. In 1982 the IIF set up the Journal of Forecasting (JoF), published with John Wiley \& Sons. After a break with Wiley in 1985 $5^{1}$ the IIF decided to start the International Journal of Forecasting (IJF), published with Elsevier since 1985. This paper provides a selective guide to the literature on time series forecasting, covering the period 1982-2005 and summarizing about 340 papers published under the "IIF-flag" out of a total of over 940 papers. The proportion of papers that concern time series forecasting has been fairly stable over time. We also review key papers and books published elsewhere that have been highly influential to various developments in the field. The works referenced comprise 380 journal papers, and 20 books and monographs.

It was felt convenient to first classify the papers according to the models (e.g. exponential smoothing, ARIMA) introduced in the time series literature, rather than putting papers under a heading associated with a particular method. For instance, Bayesian methods in general can be applied to all models. Papers not concerning a particular model were then classified according to the various problems (e.g. accuracy measures, combining) they address. In only a few cases was a subjective decision on our part needed to classify a paper under a particular section heading. To facilitate a quick overview in a particular field, the papers are listed in alphabetical order under each of the section headings.

Determining what to include and what not to include in the list of references has been a problem. There may be papers that we have missed, and papers that are also referenced by other authors in this Silver Anniversary issue. As such the review is somewhat "selective", although this does not imply that a particular paper is unimportant if it is not reviewed.

The review is not intended to be critical, but rather a (brief) historical and personal tour of the main developments. Still, a cautious reader may detect certain areas where the fruits of 25 years of intensive research interest has been limited. Conversely, clear explanations for many previously anomalous time series forecasting results have been provided by the end of 2005 . Section 13 discusses some current research directions that hold promise for the future, but of course the list is far from exhaustive.

\footnotetext{
${ }^{1}$ The IIF was involved with JoF issue 14:1 (1985)
} 


\section{Exponential smoothing}

\subsection{Preamble}

Twenty five years ago, exponential smoothing methods were often considered a collection of ad hoc techniques for extrapolating various types of univariate time series. Although exponential smoothing methods were widely used in business and industry, they had received little attention from statisticians and did not have a well-developed statistical foundation. These methods originated in the 1950s and 1960s with the work of Brown $(1959,1963)$, Holt (1957, reprinted 2004) and Winters (1960). Pegels (1969) provided a simple but useful classification of the trend and the seasonal patterns depending on whether they are additive (linear) or multiplicative (nonlinear).

Muth (1960) was the first to suggest a statistical foundation for simple exponential smoothing (SES) by demonstrating that it provided the optimal forecasts for a random walk plus noise. Further steps towards putting exponential smoothing within a statistical framework were provided by Box \& Jenkins (1970, 1976), Roberts (1982) and Abraham and Ledolter (1983, 1986), who showed that some linear exponential smoothing forecasts arise as special cases of ARIMA models. However, these results did not extend to any nonlinear exponential smoothing methods.

Exponential smoothing methods received a boost by two papers published in 1985, which laid the foundation for much of the subsequent work in this area. First, Gardner (1985) provided a thorough review and synthesis of work in exponential smoothing to that date, and extended Pegels' classification to include damped trend. This paper brought together a lot of existing work which stimulated the use of these methods and prompted a substantial amount of additional research. Later in the same year, Snyder (1985) showed that SES could be considered as arising from an innovation state space model (i.e., a model with a single source of error). Although this insight went largely unnoticed at the time, in recent years it has provided the basis for a large amount of work on state space models underlying exponential smoothing methods.

Most of the work since 1985 has involved studying the empirical properties of the methods (e.g. Bartolomei \& Sweet, 1989; Makridakis \& Hibon, 1991), proposals for new methods of estimation or initialization (Ledolter \& Abraham, 1984), evaluation of the forecasts (Sweet \& Wilson, 1988; McClain, 1988), or has concerned statistical models that can be considered to underly the methods (e.g. McKenzie, 1984). The damped multiplicative methods of Taylor (2003) provide the only genuinely new exponential smoothing methods over this period. There have, of course, been numerous studies applying exponential smoothing methods in various contexts including computer components (Gardner, 1993), air passengers (Grubb \& Masa, 2001) and production planning (Miller \& Liberatore, 1993).

Hyndman et al.'s (2002) taxonomy (extended by Taylor, 2003) provides a helpful categorization in describing the various methods. Each method consists of one of five types of trend (none, 
additive, damped additive, multiplicative and damped multiplicative) and one of three types of seasonality (none, additive and multiplicative). Thus, there are 15 different methods, the best known of which are SES (no trend, no seasonality), Holt's linear method (additive trend, no seasonality), Holt-Winters' additive method (additive trend, additive seasonality) and HoltWinters' multiplicative method (additive trend, multiplicative seasonality).

\subsection{Variations}

Numerous variations on the original methods have been proposed. For example, Carreno \& Madinaveitia (1990) and Williams \& Miller (1999) proposed modifications to deal with discontinuities, and Rosas \& Guerrero (1994) looked at exponential smoothing forecasts subject to one or more constraints. There are also variations in how and when seasonal components should be normalized. Lawton (1998) argued for renormalization of the seasonal indices at each time period, as it removes bias in estimates of level and seasonal components. Slightly different normalization schemes were given by Roberts (1982) and McKenzie (1986). Archibald \& Koehler (2003) developed new renormalization equations that are simpler to use and give the same point forecasts as the original methods.

One useful variation, part way between SES and Holt's method, is SES with drift. This is equivalent to Holt's method with the trend parameter set to zero. Hyndman \& Billah (2003) showed that this method was also equivalent to Assimakopoulos \& Nikolopoulos's (2000) "Theta method" when the drift parameter is set to half the slope of a linear trend fitted to the data. The Theta method performed extremely well in the M3-competition, although why this particular choice of model and parameters is good has not yet been determined.

There has been remarkably little work in developing multivariate versions of the exponential smoothing methods for forecasting. One notable exception is Pfeffermann \& Allon (1989) who looked at Israeli tourism data. Multivariate SES is used for process control charts (e.g. Pan, 2005), where it is called "multivariate exponentially weighted moving averages", but here the focus is not on forecasting.

\subsection{State space models}

Ord et al. (1997) built on the work of Snyder (1985) by proposing a class of innovation state space models which can be considered as underlying some of the exponential smoothing methods. Hyndman et al. (2002) and Taylor (2003) extended this to include all of the 15 exponential smoothing methods. In fact, Hyndman et al. (2002) proposed two state space models for each method, corresponding to the additive error and the multiplicative error cases. These models are not unique, and other related state space models for exponential smoothing methods are presented in Koehler et al. (2001) and Chatfield et al. (2001). It has long been known that some ARIMA models give equivalent forecasts to the linear exponential smoothing methods. The significance of the recent work on innovation state space models is that the nonlinear exponen- 
tial smoothing methods can also be derived from statistical models.

\subsection{Method selection}

Gardner \& McKenzie (1988) provided some simple rules based on the variances of differenced time series for choosing an appropriate exponential smoothing method. Tashman \& Kruk (1996) compared these rules with others proposed by Collopy \& Armstrong (1992) and an approach based on the BIC. Hyndman et al. (2002) also proposed an information criterion approach, but using the underlying state space models.

\subsection{Robustness}

The remarkably good forecasting performance of exponential smoothing methods has been addressed by several authors. Satchell \& Timmermann (1995) and Chatfield et al. (2001) showed that SES is optimal for a wide range of data generating processes. In a small simulation study, Hyndman (2001) showed that simple exponential smoothing performed better than first order ARIMA models because it is not so subject to model selection problems, particularly when data are non-normal.

\subsection{Prediction intervals}

One of the criticisms of exponential smoothing methods 25 years ago was that there was no way to produce prediction intervals for the forecasts. The first analytical approach to this problem was to assume the series were generated by deterministic functions of time plus white noise (Brown, 1963; Sweet, 1985; McKenzie, 1986; Gardner, 1985). If this was so, a regression model should be used rather than exponential smoothing methods; thus, Newbold \& Bos (1989) strongly criticized all approaches based on this assumption.

Other authors sought to obtain prediction intervals via the equivalence between exponential smoothing methods and statistical models. Johnston \& Harrison (1986) found forecast variances for the simple and Holt exponential smoothing methods for state space models with multiple sources of errors. Yar \& Chatfield (1990) obtained prediction intervals for the additive Holt-Winters' method, by deriving the underlying equivalent ARIMA model. Approximate prediction intervals for the multiplicative Holt-Winters' method were discussed by Chatfield \& Yar (1991) making the assumption that the one-step-ahead forecast errors are independent. Koehler et al. (2001) also derived an approximate formula for the forecast variance for the multiplicative Holt-Winters' method, differing from Chatfield \& Yar (1991) only in how the standard deviation of the one-step-ahead forecast error is estimated.

Ord et al. (1997) and Hyndman et al. (2002) used the underlying innovation state space model to simulate future sample paths and thereby obtained prediction intervals for all the exponential smoothing methods. Hyndman et al. (2005) used state space models to derive analytical 
prediction intervals for 15 of the 30 methods, including all the commonly-used methods. They provide the most comprehensive algebraic approach to date for handling the prediction distribution problem for the majority of exponential smoothing methods.

\subsection{Parameter space and model properties}

It is common practice to restrict the smoothing parameters to the range 0 to 1 . However, now that underlying statistical models are available, the natural (invertible) parameter space for the models can be used instead. Archibald (1990) showed that it is possible for smoothing parameters within the usual intervals to produce non-invertible models. Consequently, when forecasting, the impact of change in the past values of the series is non-negligible. Intuitively, such parameters produce poor forecasts and the forecast performance deteriorates. Lawton (1998) also discussed this problem.

\section{ARIMA}

\subsection{Preamble}

Early attempts to study time series, particularly in the nineteenth century, were generally characterized by the idea of a deterministic world. It was the major contribution of Yule (1927) who launched the notion of stochasticity in time series by postulating that every time series can be regarded as the realization of a stochastic process. Based on this simple idea, a number of time series methods have been developed since then. Workers such as Slutsky, Walker, Yaglom, and Yule first formulated the concept of autoregressive (AR) and moving average (MA) models. Wold's decomposition theorem leads to the formulation and solution of the linear forecasting problem by Kolmogorov (1941). Since then, a considerable body of literature in the area of time series dealing with the parameter estimation, identification, model checking, and forecasting has appeared; see, e.g., Newbold (1983) for an early survey.

The publication Time Series Analysis: Forecasting and Control by Box \& Jenkins (1970, 1976) integrated the existing knowledge. Moreover, these authors developed a coherent, versatile three-stage iterative cycle for time series identification, estimation, and verification (rightly known as the Box-Jenkins approach). The book has had an enormous impact on the theory and practice of modern time series analysis and forecasting. With the advent of the computer, it has popularised the use of autoregressive integrated moving average (ARIMA) models, and its extensions, in many areas of science. Indeed, forecasting discrete time series processes through univariate ARIMA models, transfer function (dynamic regression) models and multivariate (vector) ARIMA models has generated quite a few IJF papers. Often these studies were of an

\footnotetext{
${ }^{2}$ The book by Box et al. (1994) with Gregory Reinsel as a new co-author, is an updated version of the "classic" Box \& Jenkins (1970) text. It includes new material on intervention analysis, outlier detection, testing for unit roots, and process control.
} 


\begin{tabular}{|c|c|c|c|}
\hline Data set & Forecast horizon & Benchmark & Reference \\
\hline \multicolumn{4}{|l|}{ Univariate ARIMA } \\
\hline Electricity load (minutes) & $1-30$ minutes & Wiener filter & Di Caprio et al. (1983) \\
\hline $\begin{array}{l}\text { Quarterly automobile } \\
\text { insurance paid claim costs }\end{array}$ & 8 quarters & log-linear regression & Cummins \& Griepentrog (1985) \\
\hline Daily federal funds rate & 1 day & random walk & Hein \& Spudeck (1988) \\
\hline Quarterly macroeconomic data & 1-8 quarters & Wharton model & Dhrymes \& Peristiani (1988) \\
\hline Monthly department store sales & 1 month & $\begin{array}{l}\text { simple exponential } \\
\text { smoothing }\end{array}$ & $\begin{array}{l}\text { Geurts \& Kelly }(1986,1990) \text {; } \\
\text { Pack (1990) }\end{array}$ \\
\hline $\begin{array}{l}\text { Monthly demand for telephone } \\
\text { services }\end{array}$ & 3 years & univariate state space & Grambsch \& Stahel (1990) \\
\hline Yearly population totals & 20-30 years & demographic models & Pflaumer (1992) \\
\hline Monthly tourism demand & 1-24 months & $\begin{array}{l}\text { univariate state space; } \\
\text { multivariate state space }\end{array}$ & du Preez \& Witt (2003) \\
\hline \multicolumn{4}{|c|}{ Dynamic regression/Transfer function } \\
\hline $\begin{array}{l}\text { Monthly telecommunications } \\
\text { traffic }\end{array}$ & 1 month & univariate ARIMA & Layton et al. (1986) \\
\hline Weekly sales data & 2 years & n.a. & Leone (1987) \\
\hline Daily call volumes & 1 week & Holt-Winters & Bianchi et al. (1998) \\
\hline Monthly employment levels & $1-12$ months & univariate ARIMA & Weller (1989) \\
\hline $\begin{array}{l}\text { Monthly and quarterly } \\
\text { consumption of natural gas }\end{array}$ & $\begin{array}{l}1 \text { month/ } \\
1 \text { quarter }\end{array}$ & univariate ARIMA & Liu \& Lin (1991) \\
\hline $\begin{array}{l}\text { Monthly electricity } \\
\text { consumption }\end{array}$ & $1-3$ years & univariate ARIMA & Harris \& Liu (1993) \\
\hline \multicolumn{4}{|l|}{ VARIMA } \\
\hline Yearly municipal budget data & yearly (in-sample) & univariate ARIMA & Downs \& Rocke (1983) \\
\hline Monthly accounting data & 1 month & $\begin{array}{l}\text { regression, univariate, } \\
\text { ARIMA, transfer function }\end{array}$ & Hillmer et al. (1983) \\
\hline Quarterly macroeconomic data & $1-10$ quarters & $\begin{array}{l}\text { judgmental methods, } \\
\text { univariate ARIMA }\end{array}$ & Öller (1985) \\
\hline Monthly truck sales & 1-13 months & $\begin{array}{l}\text { univariate ARIMA, } \\
\text { Holt-Winters }\end{array}$ & Heuts \& Bronckers (1988) \\
\hline $\begin{array}{l}\text { Monthly hospital patient } \\
\text { movements }\end{array}$ & 2 years & $\begin{array}{l}\text { univariate ARIMA, } \\
\text { Holt-Winters }\end{array}$ & Lin (1989) \\
\hline Quarterly unemployment rate & 1-8 quarters & transfer function & Edlund \& Karlsson (1993) \\
\hline
\end{tabular}

Table 1: A list of examples of real applications.

empirical nature, using one or more benchmark methods/models as a comparison. Without pretending to be complete, Table 1 gives a list of these studies. Naturally, some of these studies are more successful than others. In all cases, the forecasting experiences reported are valuable. They have also been the key to new developments which may be summarized as follows.

\subsection{Univariate}

The success of the Box-Jenkins methodology is founded on the fact that the various models can, between them, mimic the behaviour of diverse types of series-and do so adequately without usually requiring very many parameters to be estimated in the final choice of the model. However, in the mid sixties the selection of a model was very much a matter of researcher's judgment; there was no algorithm to specify a model uniquely. Since then, many techniques and 
methods have been suggested to add mathematical rigour to the search process of an ARMA model, including Akaike's information criterion (AIC), Akaike's final prediction error (FPE), and the Bayes information criterion (BIC). Often these criteria come down to minimizing (insample) one-step-ahead forecast errors, with a penalty term for overfitting. FPE has also been generalized for multi-step-ahead forecasting (see, e.g., Bhansali, 1996, 1999), but this generalization has not been utilized by applied workers. This also seems to be the case with criteria based on cross-validation and split-sample validation (see, e.g., West, 1996) principles, making use of genuine out-of-sample forecast errors; see Peña \& Sánchez (2005) for a related approach worth considering.

There are a number of methods (cf. Box, et al., 1994) for estimating parameters of an ARMA model. Although these methods are equivalent asymptotically, in the sense that estimates tend to the same normal distribution, there are large differences in finite sample properties. In a comparative study of software packages, Newbold et al. (1994) showed that this difference can be quite substantial and, as a consequence, may influence forecasts. They recommended the use of full maximum likelihood. The effect of parameter estimation errors on probability limits of the forecasts was also noticed by Zellner (1971). He used a Bayesian analysis and derived the predictive distribution of future observations treating the parameters in the ARMA model as random variables. More recently, Kim (2003) considered parameter estimation and forecasting of AR models in small samples. He found that (bootstrap) bias-corrected parameter estimators produce more accurate forecasts than the least squares estimator. Landsman \& Damodaran (1989) presented evidence that the James-Stein ARIMA parameter estimator improves forecast accuracy relative to other methods, under an MSE loss criterion.

If a time series is known to follow a univariate ARIMA model, forecasts using disaggregated observations are, in terms of MSE, at least as good as forecasts using aggregated observations. However, in practical applications there are other factors to be considered, such as missing values in disaggregated series. Both Ledolter (1989) and Hotta (1993) analysed the effect of an additive outlier on the forecast intervals when the ARIMA model parameters are estimated. When the model is stationary, Hotta \& Cardoso Neto (1993) showed that the loss of efficiency using aggregated data is not large, even if the model is not known. Thus, prediction could be done by either disaggregated or aggregated models.

The problem of incorporating external (prior) information in the univariate ARIMA forecasts have been considered by Cholette (1982), Guerrero (1991) and de Alba (1993).

As an alternative to the univariate ARIMA methodology, Parzen (1982) proposed the ARARMA methodology. The key idea is that a time series is transformed from a long memory AR filter to a short-memory filter, thus avoiding the "harsher" differencing operator. In addition, a different approach to the 'conventional' Box-Jenkins identification step is used. In the M-competition (Makridakis et al., 1982), the ARARMA models achieved the lowest MAPE for longer forecast horizons. Hence it is surprising to find that, apart from the paper by Meade \& Smith (1985), the ARARMA methodology has not really taken off in applied work. Its ultimate value may per- 
haps be better judged by assessing the study by Meade (2000) who compared the forecasting performance of an automated and non-automated ARARMA method.

Automatic univariate ARIMA modelling has been shown to produce one-step-ahead forecasting as accurate as those produced by competent modellers (Hill \& Fildes, 1984; Libert, 1984; Poulos et al., 1987; Texter \& Ord, 1989). Several software vendors have implemented automated time series forecasting methods (including multivariate methods); see, e.g., Geriner \& Ord (1991), Tashman \& Leach (1991) and Tashman (2000). Often these methods act as black boxes. The technology of expert systems (Mélard \& Pasteels, 2000) can be used to avoid this problem. Some guidelines on the choice of an automatic forecasting method are provided by Chatfield (1988).

Rather than adopting a single AR model for all forecast horizons, Kang (2003) empirically investigated the case of using a multi-step ahead forecasting AR model selected separately for each horizon. The forecasting performance of the multi-step ahead procedure appears to depend on, among other things, optimal order selection criteria, forecast periods, forecast horizons, and the time series to be forecast.

\subsection{Transfer function}

The identification of transfer function models can be difficult when there is more than one input variable. Edlund (1984) presented a two-step method for identification of the impulse response function when a number of different input variables are correlated. Koreisha (1983) established various relationships between transfer functions, causal implications and econometric model specification. Gupta (1987) identified the major pitfalls in causality testing. Using principal component analysis, a parsimonious representation of a transfer function model was suggested by del Moral \& Valderrama (1997). Krishnamurthi et al. (1989) showed how more accurate estimates of the impact of interventions in transfer function models can be obtained by using a control variable.

\subsection{Multivariate}

The vector ARIMA (VARIMA) model is a multivariate generalization of the univariate ARIMA model. The population characteristics of VARMA processes appear to have been first derived by Quenouille $(1957,1968)$, although software to implement them only became available in the 1980s and 1990s. Since VARIMA models can accommodate assumptions on exogeneity and on contemporaneous relationships, they offered new challenges to forecasters and policy makers. Riise \& Tjøstheim (1984) addressed the effect of parameter estimation on VARMA forecasts. Cholette \& Lamy (1986) showed how smoothing filters can be built into VARMA models. The smoothing prevents irregular fluctuations in explanatory time series from migrating to the forecasts of the dependent series. To determine the maximum forecast horizon of VARMA processes, De Gooijer \& Klein (1991) established the theoretical properties of cumu- 
lated multi-step-ahead forecasts and cumulated multi-step-ahead forecast errors. Lütkepohl (1986) studied the effects of temporal aggregation and systematic sampling on forecasting, assuming that the disaggregated (stationary) variable follows a VARMA process with unknown order. Later, Bidarkota (1998) considered the same problem but with the observed variables integrated rather than stationary.

Vector autoregressions (VARs) constitute a special case of the more general class of VARMA models. In essence, a VAR model is a fairly unrestricted (flexible) approximation to the reduced form of a wide variety of dynamic econometric models. VAR models can be specified in a number of ways. Funke (1990) presented five different VAR specifications and compared their forecasting performance using monthly industrial production series. Dhrymes \& Thomakos (1998) discussed issues regarding the identification of structural VARs. Hafer \& Sheehan (1989) showed the effect on VAR forecasts of changes in the model structure. Explicit expressions for VAR forecasts in levels are provided by Ariño \& Franses (2000); see also Wieringa \& Horváth (2005). Hansson et al. (2005) used a dynamic factor model as a starting point to obtain forecasts from parsimoniously parametrised VARs.

In general, VAR models tend to suffer from 'overfitting' with too many free insignificant parameters. As a result, these models can provide poor out-of-sample forecasts, even though within-sample fitting is good; see, e.g., Liu et al. (1994) and Simkins (1995). Instead of restricting some of the parameters in the usual way, Litterman (1986) and others imposed a prior distribution on the parameters expressing the belief that many economic variables behave like a random walk. BVAR models have been chiefly used for macroeconomic forecasting (Ashley, 1988; Kunst \& Neusser, 1986; Artis \& Zhang, 1990; Holden \& Broomhead, 1990), for forecasting market shares (Ribeiro Ramos, 2003), for labor market forecasting (LeSage \& Magura, 1991), for business forecasting (Spencer, 1993), or for local economic forecasting (LeSage, 1989). Kling \& Bessler (1985) compared out-of-sample forecasts of several then-known multivariate time series methods, including Litterman's BVAR model.

The Engle-Granger (1987) concept of cointegration has raised various interesting questions regarding the forecasting ability of error correction models (ECMs) over unrestricted VARs and BVARs. Shoesmith (1992, 1995), Tegene \& Kuchler (1994) and Wang \& Bessler (2004) provided empirical evidence to suggest that ECMs outperform VARs in levels, particularly over longer forecast horizons. Shoesmith (1995), and later Villani (2001), also showed how Litterman's (1986) Bayesian approach can improve forecasting with cointegrated VARs. Reimers (1997) studied the forecasting performance of seasonally cointegrated vector time series processes using an ECM in fourth differences. Poskitt (2003) discussed the specification of cointegrated VARMA systems. Chevillon \& Hendry (2005) analyzed the relation between direct multi-step estimation of stationary and non-stationary VARs and forecast accuracy. 


\section{Seasonality}

The oldest approach to handling seasonality in time series is to extract it using a seasonal decomposition procedure such as the X-11 method. Over the past 25 years, the X-11 method and its variants (including the most recent version, X-12-ARIMA, Findley et al., 1998) have been studied extensively.

One line of research has considered the effect of using forecasting as part of the seasonal decomposition method. For example, Dagum (1982) and Huot et al. (1986) looked at the use of forecasting in X-11-ARIMA to reduce the size of revisions in the seasonal adjustment of data, and Pfeffermann et al. (1995) explored the effect of the forecasts on the variance of the trend and seasonally adjusted values.

Quenneville et al. (2003) took a different perspective and looked at forecasts implied by the asymmetric moving average filters in the X-11 method and its variants.

A third approach has been to look at the effectiveness of forecasting using seasonally adjusted data obtained from a seasonal decomposition method. Miller \& Williams $(2003,2004)$ showed that greater forecasting accuracy is obtained by shrinking the seasonal component towards zero. The commentaries on the latter paper (Findley et al., 2004; Ladiray \& Quenneville, 2004; Hyndman, 2004; Koehler, 2004; and Ord, 2004) gave several suggestions regarding implementation of this idea.

In addition to work on the X-11 method and its variants, there have also been several new methods for seasonal adjustment developed, the most important being the model based approach of TRAMO-SEATS (Gómez \& Maravall, 2001; Kaiser \& Maravall, 2005) and the nonparametric method STL (Cleveland et al., 1990). Another proposal has been to use sinusoidal models (Simmons, 1990).

When forecasting several similar series, Withycombe (1989) showed that it can be more efficient to estimate a combined seasonal component from the group of series, rather than individual seasonal patterns. Bunn \& Vassilopoulos (1993) demonstrated how to use clustering to form appropriate groups for this situation, and Bunn \& Vassilopoulos (1999) introduced some improved estimators for the group seasonal indices.

Twenty five years ago, unit root tests had only recently been invented, and seasonal unit root tests were yet to appear. Subsequently, there has been considerable work done on the use and implementation of seasonal unit root tests including Hylleberg \& Pagan (1997), Taylor (1997) and Franses \& Koehler (1998). Paap et al. (1997) and Clements \& Hendry (1997) studied the forecast performance of models with unit roots, especially in the context of level shifts.

Some authors have cautioned against the widespread use of standard seasonal unit root models for economic time series. Osborn (1990) argued that deterministic seasonal components are more common in economic series than stochastic seasonality. Franses \& Romijn (1993) sug- 
gested that seasonal roots in periodic models result in better forecasts. Periodic time series models were also explored by Wells (1997), Herwartz (1997) and Novales \& de Fruto (1997), all of whom found that periodic models can lead to improved forecast performance compared to non-periodic models under some conditions. Forecasting of multivariate periodic ARMA processes is considered by Ula (1993).

Several papers have compared various seasonal models empirically. Chen (1997) explored the robustness properties of a structural model, a regression model with seasonal dummies, an ARIMA model, and Holt-Winters' method, and found that the latter two yield forecasts that are relatively robust to model misspecification. Noakes et al. (1985), Albertson \& Aylen (1996), Kulendran \& King (1997) and Franses \& van Dijk (2005) each compared the forecast performance of several seasonal models applied to real data. The best performing model varies across the studies, depending on which models were tried and the nature of the data. There appears to be no consensus yet as to the conditions under which each model is preferred.

\section{State space and structural models and the Kalman filter}

At the start of the 1980s, state space models were only beginning to be used by statisticians for forecasting time series, although the ideas had been present in the engineering literature since Kalman's (1960) ground-breaking work. State space models provide a unifying framework in which any linear time series model can be written. The key forecasting contribution of Kalman (1960) was to give a recursive algorithm (known as the Kalman filter) for computing forecasts. Statisticians became interested in state space models when Schweppe (1965) showed that the Kalman filter provides an efficient algorithm for computing the one-step-ahead prediction errors and associated variances needed to produce the likelihood function. Shumway \& Stoffer (1982) combined the EM algorithm with the Kalman filter to give a general approach to forecasting time series using state space models, including allowing for missing observations.

A particular class of state space models, known as "dynamic linear models" (DLM), was introduced by Harrison \& Stevens (1976), who also proposed a Bayesian approach to estimation. Fildes (1983) compared the forecasts obtained using Harrison \& Steven's method with those from simpler methods such as exponential smoothing, and concluded that the additional complexity did not lead to improved forecasting performance. The modelling and estimation approach of Harrison \& Stevens was further developed by West, Harrison \& Migon (1985) and West \& Harrison (1989). Harvey $(1984,1989)$ extended the class of models and followed a nonBayesian approach to estimation. He also renamed the models as "structural models", although in later papers he uses the term "unobserved component models". Harvey (2006) provides a comprehensive review and introduction to this class of models including continuous-time and non-Gaussian variations.

These models bear many similarities with exponential smoothing methods, but have multiple 
sources of random error. In particular, the "basic structural model" (BSM) is similar to HoltWinters' method for seasonal data and includes a level, trend and seasonal component.

Ray (1989) discussed convergence rates for the linear growth structural model and showed that the initial states (usually chosen subjectively) have a non-negligible impact on forecasts. Harvey \& Snyder (1990) proposed some continuous-time structural models for use in forecasting lead time demand for inventory control. Proietti (2000) discussed several variations on the BSM and compared their properties and evaluated the resulting forecasts.

Non-Gaussian structural models have been the subject of a large number of papers, beginning with the power steady model of Smith (1979) with further development by West, Harrison \& Migon (1985). For example, these models were applied to forecasting time series of proportions by Grunwald, Raftery \& Guttorp (1993) and to counts by Harvey \& Fernandes (1989). However, Grunwald, Hamza \& Hyndman (1997) showed that most of the commonly used models have the substantial flaw of all sample paths converging to a constant when the sample space is less than the whole real line, making them unsuitable for anything other than point forecasting.

Another class of state space models, known as "balanced state space models", has been used primarily for forecasting macroeconomic time series. Mittnik (1990) provided a survey of this class of models, and Vinod \& Basu (1995) obtained forecasts of consumption, income and interest rates using balanced state space models. These models have only one source of random error and subsume various other time series models including ARMAX models, ARMA models and rational distributed lag models. A related class of state space models are the "single source of error" models that underly exponential smoothing methods; these were discussed in Section 2

As well as these methodological developments, there have been several papers proposing innovative state space models to solve practical forecasting problems. These include Coomes (1992) who used a state space model to forecast jobs by industry for local regions, and Patterson (1995) who used a state space approach for forecasting real personal disposable income.

Amongst this research on state space models, Kalman filtering, and discrete/continuous time structural models, the books by Harvey $(1989)$, West \& Harrison $(1989,1997)$ and Durbin \& Koopman (2001) have had a substantial impact on the time series literature. However, forecasting applications of the state space framework using the Kalman filter has been rather limited in the IJF. In that sense, it is perhaps not too surprising that even today, some textbook authors do not seem to realize that the Kalman filter can, for example, track a nonstationary process stably. 


\section{Nonlinear}

\subsection{Preamble}

Compared to the study of linear time series, the development of nonlinear time series analysis and forecasting is still in its infancy. The beginning of nonlinear time series analysis has been attributed to Volterra (1930). He showed that any continuous nonlinear function in $t$ could be approximated by a finite Volterra series. Wiener (1958) became interested in the ideas of functional series representation, and further developed the existing material. Although the probabilistic properties of these models have been studied extensively, the problems of parameter estimation, model fitting, and forecasting, have been neglected for a long time. This neglect can largely be attributed to the complexity of the proposed Wiener model, and its simplified forms like the bilinear model (Poskitt \& Tremayne, 1986). At the time, fitting these models led to what were insurmountable computational difficulties.

Although linearity is a useful assumption and a powerful tool in many areas, it became increasingly clear in the late 1970s and early 1980s that linear models are insufficient in many real applications. For example, sustained animal population size cycles (the well-known Canadian lynx data), sustained solar cycles (annual sunspot numbers), energy flow and amplitudefrequency relations were found not to be suitable for linear models. Accelerated by practical demands, several useful nonlinear time series models were proposed in this same period. De Gooijer \& Kumar (1992) provided an overview of the developments in this area to the beginning of the 1990s. These authors argued that the evidence for the superior forecasting performance of nonlinear models is patchy.

One factor that has probably retarded the widespread reporting of nonlinear forecasts is that up to that time it was not possible to obtain closed-form analytic expressions for multi-stepahead forecasts. However, by using the so-called Chapman-Kolmogorov relation, exact least squares multi-step-ahead forecasts for general nonlinear AR models can, in principle, be obtained through complex numerical integration. Early examples of this approach are reported by Pemberton (1987) and Al-Quassem \& Lane (1989). Nowadays, nonlinear forecasts are obtained by either Monte Carlo simulation or by bootstrapping. The latter approach is preferred since no assumptions are made about the distribution of the error process.

The monograph by Granger \& Teräsvirta (1993) has boosted new developments in estimating, evaluating, and selecting among nonlinear forecasting models for economic and financial time series. A good overview of the current state-of-the-art is IJF Special Issue 20:2 (2004). In their introductory paper Clements et al. (2004) outlined a variety of topics for future research. They concluded that "... the day is still long off when simple, reliable and easy to use nonlinear model specification, estimation and forecasting procedures will be readily available". 


\subsection{Regime-switching models}

The class of (self-exciting) threshold AR (SETAR) models has been prominently promoted through the books by Tong $(1983,1990)$. These models, which are piecewise linear models in their most basic form, have attracted some attention in the IJF. Clements \& Smith (1997) compared a number of methods for obtaining multi-step-ahead forecasts for univariate discretetime SETAR models. They concluded that forecasts made using Monte Carlo simulation are satisfactory in cases were it is known that the disturbances in the SETAR model come from a symmetric distribution. Otherwise the bootstrap method is to be preferred. Similar results were reported by De Gooijer \& Vidiella-i-Anguera (2004) for threshold VAR models. Brockwell \& Hyndman (1992) obtained one-step-ahead forecasts for univariate continuous-time threshold AR models (CTAR). Since the calculation of multi-step-ahead forecasts from CTAR models involves complicated higher dimensional integration, the practical use of CTARs is limited. The out-of-sample forecast performance of various variants of SETAR models relative to linear models has been the subject of several IJF papers, including Astatkie et al. (1997), Boero \& Marrocu (2004) and Enders \& Falk (1998).

One drawback of the SETAR model is that the dynamics change discontinuously from one regime to the other. In contrast, a smooth transition AR (STAR) model allows for a more gradual transition between the different regimes. Sarantis (2001) found evidence that STAR-type models can improve upon linear AR and random walk models in forecasting stock prices at both short term and medium term horizons. Interestingly, the recent study by Bradley \& Jansen (2004) seems to refute Sarantis' conclusion.

Can forecasts for macroeconomic aggregates like total output or total unemployment be improved by using a multi-level panel smooth STAR model for disaggregated series? This is the key issue examined by Fok et al (2005). The proposed STAR model seems to be worth investigating in more detail since it allows the parameters that govern the regime-switching to differ across states. Based on simulation experiments and empirical findings, the authors claim that improvements in one-step-ahead forecasts can indeed be achieved.

Franses et al. (2004) proposed a threshold AR(1) model that allows for plausible inference about the specific values of the parameters. The key idea is that the values of the AR parameter depend on a leading indicator variable. The resulting model outperforms other time-varying nonlinear models, including the Markov regime-switching model, in terms of forecasting.

\subsection{Functional-coefficient model}

A functional coefficient AR (FCAR or FAR) model is an AR model in which the AR coefficients are allowed to vary as a measurable smooth function of another variable, such as a lagged value of the time series itself or an exogenous variable. The FCAR model includes TAR, and STAR models as special cases, and is analogous to the generalised additive model of Hastie \& Tibshirani (1991). Chen \& Tsay (1993) proposed a modeling procedure using ideas from 
both parametric and nonparametric statistics. The approach assumes little prior information on model structure without suffering from the "curse of dimensionality"; see also Cai et al. (2000). Harvill \& Ray (2005) presented multi-step ahead forecasting results using univariate and multivariate functional coefficient (V)FCAR models. These authors restricted their comparison to three forecasting methods: the naive plug-in predictor, the bootstrap predictor, and the multi-stage predictor. Both simulation and empirical results indicate that the bootstrap method appears to give slightly more accurate forecast results. A potentially useful area of future research is whether the forecasting power of VFCAR models can be enhanced by using exogenous variables.

\subsection{Neural nets}

The artificial neural network (ANN) can be useful for nonlinear processes that have an unknown functional relationship and as a result are difficult to fit (Darbellay \& Slama, 2000). The main idea with ANNs is that inputs, or dependent variables, get filtered through one or more hidden layers each of which consist of hidden units, or nodes, before they reach the output variable. Next the intermediate output is related to the final output. Various other nonlinear models are specific versions of ANNs, where more structure is imposed; see JoF Special Issue 17:5/ 6 (1998) for some recent studies.

One major application area of ANNs is forecasting; see Zhang et al. (1998) and Hippert et al. (2001) for good surveys of the literature. Numerous studies outside the IJF have documented the successes of ANNs in forecasting financial data. However, in two editorials in this Journal, Chatfield $(1993,1995)$ questioned whether ANNs had been oversold as a miracle forecasting technique. This was followed by several papers documenting that naïve models such as the random walk can outperform ANNs (see, e.g., Church \& Curram, 1996; Callen et al., 1996; Conejo et al., 2005; Gorr et al., 1994; Tkacz, 2001). These observations are consistent with the results of an evaluating research by Adya and Collopy (1998), on the effectiveness of ANNbased forecasting in 48 studies done between 1988 and 1994.

Gorr (1994) and Hill et al. (1994) suggested that future research should investigate and better define the borderline between where ANNs and "traditional" techniques outperform one other. That theme is explored by several authors. Hill et al. (1994) noticed that ANNs are likely to work best for high frequency financial data and Balkin \& Ord (2000) also stressed the importance of a long time series to ensure optimal results from training ANNs. Qi (2001) pointed out that ANNs are more likely to outperform other methods when the input data is kept as current as possible, using recursive modelling (see also Olson \& Mossman, 2003).

A general problem with nonlinear models is the "curse of model complexity and model overparametrization". If parsimony is considered to be really important, then it is interesting to compare the out-of-sample forecasting performance of linear versus nonlinear models, using a wide variety of different model selection criteria. This issue was considered in quite some 
depth by Swanson \& White (1997). Their results suggested that a single hidden layer 'feedforward' ANN model, which has been by far the most popular in time series econometrics, offers a useful and flexible alternative to fixed specification linear models, particularly at forecast horizons greater than one-step-ahead. However, in contrast to Swanson \& White, Heravi et al. (2004) found that linear models produce more accurate forecasts of monthly seasonally unadjusted European industrial production series than ANN models. Ghiassa et al. (2005) presented a dynamic ANN and compared its forecasting performance against the traditional ANN and ARIMA models.

Times change, and it is fair to say that the risk of over-parametrization and overfitting is now recognized by many authors; see, e.g., Hippert et al. (2005) who use a large ANN (50 inputs, 15 hidden neurons, 24 outputs) to forecast daily electricity load profiles. Nevertheless, the question of whether or not an ANN is over-parametrised still remains unanswered. Some potential valuable ideas for building parsimoniously parametrised ANNs, using statistical inference, are suggested by Teräsvirta et al. (2005).

\subsection{Deterministic versus stochastic dynamics}

The possibility that nonlinearities in high-frequency financial data (e.g. hourly returns) are produced by a low-dimensional deterministic chaotic process has been the subject of a few studies published in the IJF. Cecen \& Erkal (1996) showed that it is not possible to exploit deterministic nonlinear dependence in daily spot rates in order to improve short-term forecasting. Lisi \& Medio (1997) reconstructed the state space for a number of monthly exchange rates and, using a local linear method, approximated the dynamics of the system on that space. One-step-ahead out-of-sample forecasting showed that their method outperforms a random walk model. A similar study was performed by Cao \& Soofi (1999).

\subsection{Miscellaneous}

A host of other, often less well known, nonlinear models have been used for forecasting purposes. For instance, Ludlow \& Enders (2000) adopted Fourier coefficients to approximate the various types of nonlinearities present in time series data. Herwartz (2001) extended the linear vector ECM to allow for asymmetries. Dahl \& Hylleberg (2004) compared Hamilton's (2001) flexible nonlinear regression model, ANNs, and two versions of the projection pursuit regression model. Time-varying AR models are included in a comparative study by Marcellino (2004). The nonparametric, nearest-neighbour method was applied by Fernández-Rodríguez et al. (1999). 


\section{Long memory}

When the integration parameter $d$ in an ARIMA process is fractional and greater than zero, the process exhibits long memory in the sense that observations a long time-span apart have nonnegligible dependence. Stationary long-memory models $(0<d<0.5)$, also termed fractionally differenced ARMA (FARMA) or fractionally integrated ARMA (ARFIMA) models, have been considered by workers in many fields; see Granger \& Joyeux (1980) for an introduction. One motivation for these studies is that many empirical time series have a sample autocorrelation function which declines at a slower rate than for an ARIMA model with finite orders and integer $d$.

The forecasting potential of fitted FARMA/ARFIMA models, as opposed to forecast results obtained from other time series models, has been a topic of various IJF papers and a special issue $(2002,18: 2)$. Ray (1993) undertook such a comparison between seasonal FARMA/ARFIMA models and standard (non-fractional) seasonal ARIMA models. The results show that higher order AR models are capable of forecasting the longer term well when compared with ARFIMA models. Following Ray (1993), Smith \& Yadav (1994) investigated the cost of assuming a unit difference when a series is only fractionally integrated with $d \neq 1$. Over-differencing a series will produce a loss in forecasting performance one-step-ahead, with only a limited loss thereafter. By contrast, under-differencing a series is more costly with larger potential losses from fitting a mis-specified AR model at all forecast horizons. This issue is further explored by Andersson (2000) who showed that misspecification strongly affects the estimated memory of the ARFIMA model, using a rule which is similar to the test of Öller (1985). Man (2003) argued that a suitably adapted $\operatorname{ARMA}(2,2)$ model can produce short-term forecasts that are competitive with estimated ARFIMA models. Multi-step ahead forecasts of long memory models have been developed by Hurvich (2002), and compared by Bhansali \& Koskoska (2002).

Many extensions of ARFIMA models and a comparison of their relative forecasting performance have been explored. For instance, Franses \& Ooms (1997) proposed the so-called periodic $\operatorname{ARFIMA}(0, d, 0)$ model where $d$ can vary with the seasonality parameter. Ravishankar \& Ray (2002) considered the estimation and forecasting of multivariate ARFIMA models. Baillie \& Chung (2002) discussed the use of linear trend-stationary ARFIMA models, while the paper by Beran et al. (2002) extended this model to allow for nonlinear trends. Souza \& Smith (2002) investigated the effect of different sampling rates, such as monthly versus quarterly data, on estimates of the long-memory parameter $d$. In a similar vein, Souza \& Smith (2004) looked at the effects of temporal aggregation on estimates and forecasts of ARFIMA processes. Within the context of statistical quality control, Ramjee et al. (2002) introduced a hyperbolically weighted moving average forecast-based control chart, designed specifically for nonstationary ARFIMA models. 


\section{ARCH/GARCH}

A key feature of financial time series is that large (small) absolute returns tend to be followed by large (small) absolute returns, that is, there are periods which display high (low) volatility. This phenomenon is referred to as volatility clustering in econometrics and finance. The class of autoregressive conditional heteroscedastic (ARCH) models, introduced by Engle (1982), describe the dynamic changes in conditional variance as a deterministic (typically quadratic) function of past returns. Because the variance is known at time $t-1$, one-step-ahead forecasts are readily available. Next, multi-step-ahead forecasts can be computed recursively. A more parsimonious model than ARCH is the so-called generalized ARCH (GARCH) model (Bollerslev, 1986; Taylor, 1986) where additional dependencies are permitted on lags of the conditional variance. A GARCH model has an ARMA-type representation, so that many of the properties of both models are similar.

The GARCH family, and many of its extensions, are extensively surveyed in, e.g., Bollerslev et al. (1992), Bera \& Higgins (1993), and Diebold \& Lopez (1995). Not surprising many of the theoretical works appeared in the econometric literature. On the other hand, it is interesting to note that neither the IJF nor the JoF became an important forum for publications on the relative forecasting performance of GARCH-type models and the forecasting performance of various other volatility models in general. As can be seen below, only very few IJF/JoF-papers dealt with this topic.

Sabbatini \& Linton (1998) showed that the simple (linear) GARCH $(1,1)$ model provides a good parametrization for the daily returns on the Swiss market index. However, the quality of the out-of-sample forecasts suggests that this result should be taken with caution. Franses \& Ghijsels (1999) stressed that this feature can be due to neglected additive outliers (AO). They noted that GARCH models for AO-corrected returns result in improved forecasts of stock market volatility. Brooks (1998) finds no clear-cut winner when comparing one-step-ahead forecasts from standard (symmetric) GARCH-type models, with those of various linear models, and ANNs. At the estimation level, Brooks et al. (2001) argued that standard econometric software packages can produce widely varying results. Clearly, this may have some impact on the forecasting accuracy of GARCH models. This observation is very much in the spirit of Newbold et al (1994), referenced in Subsection 3.2, for univariate ARMA models. Outside the IJF, multi-step-ahead prediction in ARMA models with GARCH in mean effects was considered by Karanasos (2001). His method can be employed in the derivation of multi-step predictions from more complicated models, including multivariate GARCH.

Using two daily exchange rates series, Galbraith \& Kisinbay (2005) compared the forecast content functions both from the standard GARCH model and from a fractionally integrated GARCH (FIGARCH) model (Baillie et al., 1996). Forecasts of conditional variances appear to have information content of approximately 30 trading days. Another conclusion is that forecasts by autoregressive projection on past realized volatilities provide better results than fore- 
casts based on GARCH, estimated by quasi-maximum likelihood, and FIGARCH models. This seems to confirm earlier results of Bollerslev and Wright (2001), for example. One often heard criticism of these models (FIGARCH and its generalizations) is that there is no economic rationale for financial forecast volatitility to have long memory. For a more fundamental point of criticism of the use of long-memory models we refer to Granger (2002).

Empirically, returns and conditional variance of next period's returns are negatively correlated. That is, negative (positive) returns are generally associated with upward (downward) revisions of the conditional volatility. This phenomenon is often referred to as asymmetric volatility in the literature; see, e.g., Engle and $\mathrm{Ng}$ (1993). It motivated researchers to develop various asymmetric GARCH-type models (including regime-switching GARCH); see, e.g., Hentschel (1995) and Pagan (1996) for overviews. Awartani \& Corradi (2005) investigated the impact of asymmetries on the out-of-sample forecast ability of different GARCH models, at various horizons.

Besides GARCH many other models have been proposed for volatility-forecasting. Poon \& Granger (2003), in a landmark paper, provide an excellent and carefully conducted survey of the research in this area in the last 20 years. They compared the volatility forecast findings in 93 published and working papers. Important insights are provided on issues like forecast evaluation, the effect of data frequency on volatility forecast accuracy, measurement of "actual volatility", the confounding effect of extreme values, and many more. The survey found that option-implied volatility provides more accurate forecasts than time series models. Among the time series models (44 studies) there was no clear winner between the historical volatility models (including random walk, historical averages, ARFIMA, and various forms of exponential smoothing) and GARCH-type models (including ARCH and its various extensions), but both classes of models outperform the stochastic volatility model; see also Poon \& Granger (2005) for an update on these findings.

The Poon \& Granger survey paper contains many issues for further study. For example, asymmetric GARCH models came out relatively well in the forecast contest. However, it is unclear to what extent this is due to asymmetries in the conditional mean, asymmetries in the conditional variance, and/or asymmetries in high order conditional moments. Another issue for future research concerns the combination of forecasts. The results in two studies (Doidge \& Wei, 1998; Kroner et al., 1995) find combining to be helpful, but another study (Vasilellis \& Meade, 1996) does not. It will be also useful to examine the volatility-forecasting performance of multivariate GARCH-type models and multivariate nonlinear models, incorporating both temporal and contemporaneous dependencies; see also Engle (2002) for some further possible areas of new research. 


\section{Count data forecasting}

Count data occur frequently in business and industry, especially in inventory data where they are often called "intermittent demand data". Consequently, it is surprising that so little work has been done on forecasting count data. Some work has been done on ad hoc methods for forecasting count data, but few papers have appeared on forecasting count time series using stochastic models.

Most work on count forecasting is based on Croston (1972) who proposed using SES to independently forecast the non-zero values of a series and the time between non-zero values. Willemain et al. (1994) compared Croston's method to SES and found that Croston's method was more robust, although these results were based on MAPEs which are often undefined for count data. The conditions under which Croston's method does better than SES were discussed in Johnston \& Boylan (1996). Willemain et al. (2004) proposed a bootstrap procedure for intermittent demand data which was found to be more accurate than either SES or Croston's method on the nine series evaluated.

Evaluating count forecasts raises difficulties due to the presence of zeros in the observed data. Syntetos \& Boylan (2005) proposed using the Relative Mean Absolute Error (see Section 10), while Willemain et al. (2004) recommended using the probability integral transform method of Diebold et al. (1998).

Grunwald et al. (2000) surveyed many of the stochastic models for count time series, using simple first-order autoregression as a unifying framework for the various approaches. One possible model, explored by Brännäs (1995), assumes the series follows a Poisson distribution with a mean that depends on an unobserved and autocorrelated process. An alternative integer-valued MA model was used by Brännäs et al. (2002) to forecast occupancy levels in Swedish hotels.

The forecast distribution can be obtained by simulation using any of these stochastic models, but how to summarize the distribution is not obvious. Freeland \& McCabe (2004) proposed using the median of the forecast distribution, and gave a method for computing confidence intervals for the entire forecast distribution in the case of integer-valued autoregressive (INAR) models of order 1. McCabe \& Martin (2005) further extended these ideas by presenting a Bayesian methodology for forecasting from the INAR class of models.

A great deal of research on count time series has also been done in the biostatistical area (see, for example, Diggle et al. 2002). However, this usually concentrates on analysis of historical data with adjustment for autocorrelated errors, rather than using the models for forecasting. Nevertheless, anyone working in count forecasting ought to be abreast of research developments in the biostatistical area also. 


\begin{tabular}{|c|c|c|}
\hline$\overline{\mathrm{MSE}}$ & Mean Squared Error & $=\operatorname{mean}\left(e_{t}^{2}\right)$ \\
\hline RMSE & Root Mean Squared Error & $=\sqrt{\mathrm{MSE}}$ \\
\hline MAE & Mean Absolute Error & $=\operatorname{mean}\left(\left|e_{t}\right|\right)$ \\
\hline MdAE & Median Absolute Error & $=\operatorname{median}\left(\left|e_{t}\right|\right)$ \\
\hline MAPE & Mean Absolute Percentage Error & $=\operatorname{mean}\left(\left|p_{t}\right|\right)$ \\
\hline MdAPE & Median Absolute Percentage Error & $=\operatorname{median}\left(\left|p_{t}\right|\right)$ \\
\hline SMAPE & Symmetric Mean Absolute Percentage Error & $=\operatorname{mean}\left(2\left|Y_{t}-F_{t}\right| /\left(Y_{t}+F_{t}\right)\right)$ \\
\hline sMdAPE & Symmetric Median Absolute Percentage Error & $=\operatorname{median}\left(2\left|Y_{t}-F_{t}\right| /\left(Y_{t}+F_{t}\right)\right)$ \\
\hline MRAE & Mean Relative Absolute Error & $=\operatorname{mean}\left(\left|r_{t}\right|\right)$ \\
\hline MdRAE & Median Relative Absolute Error & $=\operatorname{median}\left(\left|r_{t}\right|\right)$ \\
\hline GMRAE & Geometric Mean Relative Absolute Error & $=\operatorname{gmean}\left(\left|r_{t}\right|\right)$ \\
\hline RelMAE & Relative Mean Absolute Error & $=\mathrm{MAE} / \mathrm{MAE}_{b}$ \\
\hline RelRMSE & Relative Root Mean Squared Error & $=\mathrm{RMSE} / \mathrm{RMSE}_{b}$. \\
\hline LMR & Log Mean Squared Error Ratio & $=\log ($ RelMSE $)$ \\
\hline PB & Percentage Better & $=100$ mean $\left(I\left\{\left|r_{t}\right|<1\right\}\right)$ \\
\hline PB(MAE) & Percentage Better (MAE) & $=100 \operatorname{mean}\left(I\left\{\mathrm{MAE}<\mathrm{MAE}_{b}\right\}\right)$ \\
\hline PB(MSE) & Percentage Better (MSE) & $=100$ mean $\left(I\left\{\mathrm{MSE}<\mathrm{MSE}_{b}\right\}\right)$ \\
\hline
\end{tabular}

Table 2: Commonly used forecast accuracy measures. Here $I\{u\}=1$ if $u$ is true and 0 otherwise.

\section{Forecast evaluation and accuracy measures}

A bewildering array of accuracy measures have been used to evaluate the performance of forecasting methods. Some of them are listed in the early survey paper of Mahmoud (1984). We first define the most common measures.

Let $Y_{t}$ denote the observation at time $t$ and $F_{t}$ denote the forecast of $Y_{t}$. Then define the forecast error $e_{t}=Y_{t}-F_{t}$ and the percentage error as $p_{t}=100 e_{t} / Y_{t}$. An alternative way of scaling is to divide each error by the error obtained with another standard method of forecasting. Let $r_{t}=e_{t} / e_{t}^{*}$ denote the relative error where $e_{t}^{*}$ is the forecast error obtained from the base method. Usually, the base method is the "naïve method" where $F_{t}$ is equal to the last observation. We use the notation mean $\left(x_{t}\right)$ to denote the sample mean of $\left\{x_{t}\right\}$ over the period of interest (or over the series of interest). Analogously, we use median $\left(x_{t}\right)$ for the sample median and gmean $\left(x_{t}\right)$ for the geometric mean. The mostly commonly used methods are defined in Table 2 on the following page where the subscript $b$ refers to measures obtained from the base method.

Note that Armstrong \& Collopy (1992) referred to RelMAE as CumRAE, and that RelRMSE is also known as Theil's $U$ statistic (Theil, 1966, Chapter 2) and is sometimes called $U 2$. In addition to these, the average ranking (AR) of a method relative to all other methods considered, has sometimes been used.

The evolution of measures of forecast accuracy and evaluation can be seen through the measures used to evaluate methods in the major comparative studies that have been undertaken. In the original M-competition (Makridakis et al., 1982), measures used included the MAPE, MSE, 
AR, MdAPE and PB. However, as Chatfield (1988) and Armstrong \& Collopy (1992) pointed out, the MSE is not appropriate for comparison between series as it is scale dependent. Fildes \& Makridakis (1988) contained further discussion on this point. The MAPE also has problems when the series has values close to (or equal to) zero, as noted by Makridakis et al. (1998, p.45). Excessively large (or infinite) MAPEs were avoided in the M-competitions by only including data that were positive. However, this is an artificial solution that is impossible to apply in all situations.

In 1992, one issue of IJF carried two articles and several commentaries on forecast evaluation measures. Armstrong \& Collopy (1992) recommended the use of relative absolute errors, especially the GMRAE and MdRAE, despite the fact that relative errors have infinite variance and undefined mean. They recommended "winsorizing" to trim extreme values which will partially overcome these problems, but which adds some complexity to the calculation and a level of arbitrariness as the amount of trimming must be specified. Fildes (1992) also preferred the GMRAE although he expressed it in an equivalent form as the square root of the geometric mean of squared relative errors. This equivalence does not seem to have been noticed by any of the discussants in the commentaries of Ahlburg et al. (1992).

The study of Fildes et al. (1998), which looked at forecasting telecommunications data, used MAPE, MdAPE, PB, AR, GMRAE and MdRAE, taking into account some of the criticism of the methods used for the M-competition.

The M3-competition (Makridakis \& Hibon, 2000) used three different measures of accuracy: MdRAE, sMAPE and sMdAPE. The "symmetric" measures were proposed by Makridakis (1993) in response to the observation that the MAPE and MdAPE have the disadvantage that they put a heavier penalty on positive errors than on negative errors. However, these measures are not as "symmetric" as their name suggests. For the same value of $Y_{t}$, the value of $2\left|Y_{t}-F_{t}\right| /\left(Y_{t}+F_{t}\right)$ has a heavier penalty when forecasts are high compared to when forecasts are low. See Goodwin \& Lawton (1999) and Koehler (2001) for further discussion on this point.

Notably, none of the major comparative studies have used relative measures (as distinct from measures using relative errors) such as RelMAE or LMR. The latter was proposed by Thompson (1990) who argued for its use based on its good statistical properties. It was applied to the M-competition data in Thompson (1991).

Apart from Thompson (1990), there has been very little theoretical work on the statistical properties of these measures. One exception is Wun \& Pearn (1991) who looked at the statistical properties of MAE.

A novel alternative measure of accuracy is "time distance" which was considered by Granger \& Jeon $(2003 a, b)$. In this measure, the leading and lagging properties of a forecast are also captured. Again, this measure has not been used in any major comparative study.

A parallel line of research has looked at statistical tests to compare forecasting methods. An 
early contribution was Flores (1989). The best known approach to testing differences between the accuracy of forecast methods is the Diebold-Mariano (1995) test. A size-corrected modification of this test was proposed by Harvey et al. (1997). McCracken (2004) looked at the effect of parameter estimation on such tests and provided a new method for adjusting for parameter estimation error.

Another problem in forecast evaluation, and more serious than parameter estimation error, is "data sharing" - the use of the same data for many different forecasting methods. Sullivan et al. (2003) proposed a bootstrap procedure designed to overcome the resulting distortion of statistical inference.

An independent line of research has looked at the theoretical forecasting properties of time series models. An important contribution along these lines was Clements \& Hendry (1993) who showed that the theoretical MSE of a forecasting model was not invariant to scale-preserving linear transformations such as differencing of the data. Instead, they proposed the "generalized forecast error second moment" (GFESM) criterion which does not have this undesirable property. However, such measures are difficult to apply empirically and the idea does not appear to be widely used.

\section{Combining}

Combining, mixing, or pooling quantitativ $\mathrm{f}^{3}$ forecasts obtained from very different time series methods and different sources of information has been studied for the past three decades. Important early contributions in this area were made by Bates \& Granger (1969), Newbold \& Granger (1974) and Winkler \& Makridakis (1983). Compelling evidence on the relative efficiency of combined forecasts, usually defined in terms of forecast error variances, was summarized by Clemen (1989) in a comprehensive bibliography review.

Numerous methods for selecting the combining weights have been proposed. The simple average is the most-widely used combining method (see Clemen's review, and Bunn, 1985), but the method does not utilize past information regarding the precision of the forecasts or the dependence among the forecasts. Another simple method is a linear mixture of the individual forecasts with combining weights determined by OLS (assuming unbiasedness) from the matrix of past forecasts and the vector of past observations (Granger \& Ramanathan, 1984). However, the OLS estimates of the weights are inefficient due to the possible presence of serial correlation in the combined forecast errors. Aksu \& Gunter (1992) and Gunter (1992) investigated this problem in some detail. They recommended the use of OLS combination forecasts with the weights restricted to sum to unity.

Rather than using fixed weights, Deutsch et al. (1994) allowed them to change through time using regime-switching models and STAR models. Another time-dependent weighting scheme was proposed by Fiordaliso (1998), who used a fuzzy system to combine a set of individual

\footnotetext{
${ }^{3}$ See Kamstra \& Kennedy (1998) for a computationally-convenient method of combining qualitative forecasts.
} 
forecasts in a nonlinear way. Diebold \& Pauly (1990) used Bayesian shrinkage techniques to allow the incorporation of prior information into the estimation of combining weights. Combining forecasts from very similar models, with weights sequentially updated, was considered by Zou \& Yang (2004).

Combining weights determined from time-invariant methods can lead to relatively poor forecasts if nonstationarity among component forecasts occurs. Miller et al. (1992) examined the effect of 'location-shift' nonstationarity on a range of forecast combination methods. Tentatively they concluded that the simple average beats more complex combination devices; see also Hendry \& Clements (2002) for more recent results. The related topic of combining forecasts from linear and some nonlinear time series models, with OLS weights as well as weights determined by a time-varying method, was addressed by Terui \& van Dijk (2002).

The shape of the combined forecast error distribution and the corresponding stochastic behaviour was studied by de Menezes \& Bunn (1998) and Taylor \& Bunn (1999). For non-normal forecast error distributions skewness emerges as a relevant criterion for specifying the method of combination. Some insights into why competing forecasts may be fruitfully combined to produce a forecast superior to individual forecasts were provided by Fang (2003), using forecast encompassing tests. Hibon \& Evgeniou (2005) proposed a criterion to select among forecasts and their combinations.

\section{Prediction intervals and densities}

The use of prediction intervals, and more recently prediction densities, has become much more common over the past twenty five years as practitioners have come to understand the limitations of point forecasts. An important and thorough review of interval forecasts is given by Chatfield (1993), summarizing the literature to that time.

Unfortunately, there is still some confusion on terminology with many authors using "confidence interval" instead of "prediction interval". A confidence interval is for a model parameter whereas a prediction interval is for a random variable. Almost always, forecasters will want prediction intervals-intervals which contain the true values of future observations with specified probability.

Most prediction intervals are based on an underlying stochastic model. Consequently, there has been a large amount of work on formulating appropriate stochastic models underlying some common forecasting procedures (see, e.g., Section 2 on Exponential Smoothing).

The link between prediction interval formulae and the model from which they are derived has not always been correctly observed. For example, the prediction interval appropriate for a random walk model was applied by Makridakis \& Hibon (1987) and Lefrançois (1989) to forecasts obtained from many other methods. This problem was noted by Koehler (1990) and 
Chatfield \& Koehler (1991).

With most model-based prediction intervals for time series, the uncertainty associated with model selection and parameter estimation is not accounted for. Consequently, the intervals are too narrow. There has been considerable research on how to make model-based prediction intervals have more realistic coverage. A series of papers on using the bootstrap to compute prediction intervals for an AR model has appeared beginning with Masarotto (1990), and including McCullough (1994, 1996), Grigoletto (1998), Clements \& Taylor (2001) and Kim (2004b). Similar procedures for other models have also been considered including ARIMA models (Pascual et al., 2001, 2004, 2005), Wall \& Stoffer (2002), VAR (Kim, 1999, 2004a), ARCH (Reeves, 2005) and regression (Lam \& Veall, 2002). It seems likely that such bootstrap methods will become more widely used as computing speeds increase due to their better coverage properties.

When the forecast error distribution is non-normal, finding the entire forecast density is useful as a single interval may no longer provide an adequate summary of the expected future. A review of density forecasting is provided by Tay \& Wallis (2000), along with several other articles in the same special issue of the JoF. Summarizing, a density forecast has been the subject of some interesting proposals including "fan charts" (Wallis, 1999) and "highest density regions" (Hyndman, 1995). The use of these graphical summaries has grown rapidly in recent years as density forecasts have become relatively widely used.

As prediction intervals and forecast densities have become more commonly used, attention has turned to their evaluation and testing. Diebold et al. (1998) introduced the remarkably simple "probability integral transform" method which can be used to evaluate a univariate density. This approach has become widely used in a very short period of time and has been a key research advance in this area. The idea is extended to multivariate forecast densities in Diebold et al. (1999).

Other approaches to interval and density evaluation are given by Wallis (2003) who proposed chi-squared tests for both intervals and densities, and Clements \& Smith (2002) who discussed some simple but powerful tests when evaluating multivariate forecast densities.

\section{A look to the future}

In the preceding sections we have looked back at the time series forecasting history of the IJF, in the hope that the past may shed light on the present. But a silver anniversary is also a good time to look ahead. In doing so, it is interesting to reflect on the proposals for research in time series forecasting identified in a set of related papers by Ord, Cogger and Chatfield published in this Journal more than 15 years ago 4

\footnotetext{
${ }^{4}$ Outside the $I J F$, good reviews on the past and future of time series methods are given by Dekimpe \& Hanssens (2000) in marketing, and by Tsay (2000) in statistics. Casella et al. (2000) discussed a large number of potential research topics in the theory and methods of statistics. We daresay that some of these topics will attract the interest
} 
Chatfield (1988) stressed the need for future research on developing multivariate methods with an emphasis on making them more of a practical proposition. Ord (1988) also noted that not much work had been done on multiple time series models, including multivariate exponential smoothing. Eighteen years later, multivariate time series forecasting is still not widely applied despite considerable theoretical advances in this area. We suspect that two reasons for this are: a lack of empirical research on robust forecasting algorithms for multivariate models; and a lack of software that is easy to use. Some of the methods that have been suggested (e.g. VARIMA models) are difficult to estimate because of the large numbers of parameters involved. Others, such as multivariate exponential smoothing, have not received sufficient theoretical attention to be ready for routine application. One approach to multivariate time series forecasting is to use dynamic factor models. These have recently shown promise in theory (Stock \& Watson, 2002; Forni et al., 2005) and application (e.g. Peña \& Poncela, 2004), and we suspect they will become much more widely used in the years ahead.

Ord (1988) also indicated the need for deeper research in forecasting methods based on nonlinear models. While many aspects of nonlinear models have been investigated in the IJF, they merit continued research. For instance, there is still no clear consensus that forecasts from nonlinear models substantively outperform those from linear models (see, e.g., Stock \& Watson, 1999).

Other topics suggested by Ord (1988) include the need to develop model selection procedures that make effective use of both data and prior knowledge, and the need to specify objectives for forecasts and develop forecasting systems that address those objectives. These areas are still in need of attention, and we believe that future research will contribute tools to solve these problems.

Given the frequent misuse of methods based on linear models with Gaussian i.i.d. distributed errors, Cogger (1988) argued that new developments in the area of 'robust' statistical methods should receive more attention within the time series forecasting community. A robust procedure is expected to work well when there are outliers or location shifts in the data that are hard to detect. Robust statistics can be based on both parametric and nonparametric methods. An example of the latter is the Koenker-Bassett (1978) concept of regression quantiles investigated by Cogger. In forecasting, these can be applied as univariate and multivariate conditional quantiles. One important area of application is in estimating risk management tools such as Value-at-Risk. Recently, Engle \& Manganelli (2004) made a start in this direction, proposing a conditional value at risk model. We expect to see much future research in this area.

A related topic in which there has been a great deal of recent research activity is density forecasting (see Section 12, where the focus is on the probability density of future observations rather than the mean or variance. For instance, Yao \& Tong (1995) proposed the concept of conditional percentile prediction interval. Its width is no longer a constant, as in the case of linear models, but may vary with respect to the position in the state space from which forecasts

of time series forecasters. 
are being made; see also De Gooijer \& Gannoun (2000) and Polonik \& Yao (2000).

Clearly, the area of improved forecast intervals requires further research. This is in agreement with Armstrong (2001) who listed 23 principles in great need of research including item 14:13: "For prediction intervals, incorporate the uncertainty associated with the prediction of the explanatory variables."

In recent years, non-Gaussian time series have begun to receive considerable attention and forecasting methods are slowly being developed. One particular area of non-Gaussian time series that has important applications is time series taking positive values only. Two important areas in finance in which these arise are realized volatility and the duration between transactions. Work on such series is still in its infancy. Important contributions to date have been Engle and Russell's (1998) “Autoregressive Conditional Duration" model and Andersen et al. (2003). Because of the importance of these applications, we expect much more work in this area in the next few years.

While forecasting non-Gaussian time series with a continuous sample space has begun to receive research attention, especially in the context of finance, forecasting time series with a discrete sample space (such as time series of counts) is still its infancy (see Section 9). Such data are very prevalent in business and industry, and there are many unresolved theoretical and practical problems associated with count forecasting, therefore we also expect much productive research in this area in the near future.

In the past fifteen years, some IJF authors have tried to identify new important research topics. Both De Gooijer (1990) and Clements (2003) in two editorials, and Ord as a part of a discussion paper by Dawes et al. (1994), suggested more work on combining forecasts. Although the topic has received a fair amount of attention (see Section 11) there are still several open questions. For instance, what is the "best" combining method for linear and nonlinear models, and what prediction interval can be put around the combined forecast? A good starting point for further research in this area is Teräsvirta (2006); see also Armstrong (2001, items 12.5-12.7). Recently, Stock \& Watson (2004) discussed the 'forecast combination puzzle', namely the repeated empirical finding that simple combinations such as averages outperform more sophisticated combinations which theory suggests should do better. This is an important practical issue that will no doubt receive further research attention in the future.

Changes in data collection and storage will also lead to new research directions. For example, in the past, panel data (called longitudinal data in biostatistics) have usually been available where the time series dimension $t$ has been small whilst the cross-section dimension $n$ is large. However, nowadays in many applied areas such as marketing, large datasets can be easily collected with $n$ and $t$ both large. Extracting features from megapanels of panel data is the subject of "functional data analysis"; see, e.g., Ramsay \& Silverman $(1997,2005)$. Yet, the problem of making multi-step ahead forecasts based on functional data is still open for both theoretical and applied research. Because of the increasing prevalence of this kind of data, we expect this 
to be a fruitful future research area.

Large data sets also lend themselves to highly computationally intensive methods. While neural networks have been used in forecasting for more than a decade now, there are many outstanding issues associated with their use and implementation, including when they are likely to outperform other methods. Other methods involving heavy computation (e.g. bagging and boosting) are even less understood in the forecasting context. With the availability of very large data sets and high powered computers, we expect this to be an important area of research in the coming years.

Looking back, the field of time series forecasting is vastly different from what it was 25 years ago when the IIF was formed. It has grown up with the advent of greater computing power, better statistical models, and more mature approaches to forecast calculation and evaluation. But there is much to be done, with many problems still unsolved and many new problems arising.

When the IIF celebrates its Golden Anniversary in 25 years time, we hope there will be another review paper summarizing the main developments on time series forecasting. Besides the topics mentioned above, we also predict that such a review will shed more light on Armstrong's 23 open research problems for forecasters. In this sense it is interesting to mention David Hilbert who, in his 1900 address to the Paris International Congress of Mathematicians, listed 23 challenging problems for mathematicians of the twentieth century to work on. Many of Hilbert's problems have resulted in an explosion of research stemming from the confluence of several areas of mathematics and physics. We hope that the ideas, problems, and observations presented in this review provide a similar research impetus for those working in different areas of time series analysis and forecasting.

\section{Acknowledgments}

We are grateful to Robert Fildes and Andrey Kostenko for valuable comments. We also thank two anonymous referees and the editor for many helpful comments and suggestions that resulted in a substantial improvement of this manuscript. 


\section{References}

\section{Section 2. Exponential smoothing}

Abraham, B., \& Ledolter, J. (1983). Statistical methods for forecasting, New York: John Wiley \& Sons.

Abraham, B., \& Ledolter, J. (1983). Forecast functions implied by autoregressive integrated moving average models and other related forecast procedures. International Statistical Review, 54, 51-66.

Archibald, B.C. (1990). Parameter space of the Holt-Winters model. International Journal of Forecasting, 6, 199-209.

Archibald, B.C., \& Koehler, A.B. (2003). Normalization of seasonal factors in Winters methods. International Journal of Forecasting, 19, 143-148.

Assimakopoulos, V., \& Nikolopoulos, K. (2000). The theta model: A decomposition approach to forecasting. International Journal of Forecasting, 16, 521-530.

Bartolomei, S.M., \& Sweet, A.L. (1989). A note on a comparison of exponential smoothing methods for forecasting seasonal series. International Journal of Forecasting, 5, 111-116.

Brown, R.G. (1959). Statistical forecasting for inventory control, New York: McGraw-Hill.

Brown, R.G. (1963). Smoothing, forecasting and prediction of discrete time series, Englewood Cliffs, NJ: Prentice-Hall.

Carreno, J., \& Madinaveitia, J. (1990). A modification of time series forecasting methods for handling announced price increases. International Journal of Forecasting, 6, 479-484.

Chatfield, C., Koehler, A.B., Ord, J.K., \& Snyder, R.D. (2001). A new look at models for exponential smoothing. The Statistician, 50, 147-159.

Chatfield, C., \& Yar, M. (1991). Prediction intervals for multiplicative Holt-Winters. International Journal of Forecasting, 7, 31-37.

Collopy, F., \& Armstrong, J.S. (1992). Rule-based forecasting: development and validation of an expert systems approach to combining time series extrapolations. Management Science, 38, 1394-1414.

Gardner, Jr., E.S. (1985). Exponential smoothing: the state of the art. Journal of Forecasting, 4, 1-38 (with commentaries).

Gardner, Jr., E.S. (1993). Forecasting the failure of component parts in computer systems: A case study. International Journal of Forecasting, 9, 245-253.

Gardner, Jr., E.S., \& McKenzie, E. (1988). Model identification in exponential smoothing. Journal of the Operational Research Society, 39, 863-867.

Grubb, H., \& Masa, A. (2001). Long lead-time forecasting of UK air passengers by Holt-Winters methods with damped trend. International Journal of Forecasting, 17, 71-82.

Holt, C.C. (1957). Forecasting seasonals and trends by exponentially weighted averages. O.N.R. Memorandum 52/1957, Carnegie Institute of Technology. Reprinted with discussion in 2004, International Journal of Forecasting, 20, 5-13.

Hyndman, R.J. (2001). Its time to move from what to why. International Journal of Forecasting, 17, 567-570.

Hyndman, R.J., \& Billah, B. (2003). Unmasking the Theta method. International Journal of Forecasting, 19, 287-290.

Hyndman, R.J., Koehler, A.B., Ord, J.K., \& Snyder, R.D. (2005). Prediction intervals for exponential smoothing state space models. Journal of Forecasting, 24, 17-37.

Hyndman, R.J., Koehler, A.B., Snyder, R.D., \& Grose, S. (2002). A state space framework for automatic forecasting using exponential smoothing methods. International Journal of Forecasting, 18, 439-454.

Johnston, F.R., \& Harrison, P.J. (1986). The variance of lead-time demand. Journal of Operational Research Society, 37, 303-308. 
Koehler, A.B., Snyder, R.D., \& Ord, J.K. (2001). Forecasting models and prediction intervals for the multiplicative Holt-Winters method. International Journal of Forecasting, 17, 269-286.

Lawton, R. (1998). How should additive Holt-Winters estimates be corrected? International Journal of Forecasting, 14, 393-403.

Ledolter, J., \& Abraham, B. (1984). Some comments on the initialization of exponential smoothing. Journal of Forecasting, 3, 79-84.

Makridakis, S., \& Hibon, M. (1991). Exponential smoothing: The effect of initial values and loss function on post-sample forecasting accuracy. International Journal of Forecasting, 7, 317-330.

McClain, J.G. (1988). Dominant tracking signals. International Journal of Forecasting, 4, 563-572.

McKenzie, E. (1984). General exponential smoothing and the equivalent ARMA process. Journal of Forecasting, 3, 333-344.

McKenzie, E. (1986). Error analysis for Winters additive seasonal forecasting system. International Journal of Forecasting, 2, 373-382.

Miller, T., \& Liberatore, M. (1993). Seasonal exponential smoothing with damped trends. An application for production planning. International Journal of Forecasting, 9, 509-515.

Muth, J.F. (1960). Optimal properties of exponentially weighted forecasts. Journal of the American Statistical Association, 55, 299-306.

Newbold, P., \& Bos, T. (1989). On exponential smoothing and the assumption of deterministic trend plus white noise data-generating models. International Journal of Forecasting, 5, 523-527.

Ord, J.K., Koehler, A.B., \& Snyder, R.D. (1997). Estimation and prediction for a class of dynamic nonlinear statistical models. Journal of American Statistical Association, 92, 1621-1629.

Pan, X. (2005). An alternative approach to multivariate EWMA control chart. Journal of Applied Statistics, $32,695-705$.

Pegels, C.C. (1969). Exponential smoothing: some new variations. Management Science, 12, 311-315.

Pfeffermann, D., \& Allon, J. (1989). Multivariate exponential smoothing: methods and practice. International Journal of Forecasting, 5, 83-98.

Roberts, S.A. (1982). A general class of Holt-Winters type forecasting models. Management Science, $28,808-820$.

Rosas, A.L., \& Guerrero, V.M. (1994). Restricted forecasts using exponential smoothing techniques. International Journal of Forecasting, 10, 515-527.

Satchell, S., \& Timmermann, A. (1995). On the optimality of adaptive expectations: Muth revisited. International Journal of Forecasting, 11, 407-416.

Snyder, R.D. (1985). Recursive estimation of dynamic linear statistical models. Journal of the Royal Statistical Society (B), 47, 272-276.

Sweet, A.L. (1985). Computing the variance of the forecast error for the Holt-Winters seasonal models. Journal of Forecasting, 4, 235-243.

Sweet, A.L., \& Wilson, J.R. (1988). Pitfalls in simulation-based evaluation of forecast monitoring schemes. International Journal of Forecasting, 4, 573-579.

Tashman, L., \& Kruk, J.M. (1996). The use of protocols to select exponential smoothing procedures: A reconsideration of forecasting competitions. International Journal of Forecasting, 12, 235-253.

Taylor, J.W. (2003). Exponential smoothing with a damped multiplicative trend. International Journal of Forecasting, 19, 273-289.

Williams, D.W., \& Miller, D. (1999). Level-adjusted exponential smoothing for modeling planned discontinuities. International Journal of Forecasting, 15, 273-289.

Winters, P.R. (1960). Forecasting sales by exponentially weighted moving averages. Management Science, 
$6,324-342$.

Yar, M., \& Chatfield, C. (1990). Prediction intervals for the Holt-Winters forecasting procedure. International Journal of Forecasting, 6, 127-137.

\section{Section 3. ARIMA}

de Alba, E. (1993). Constrained forecasting in autoregressive time series models: A Bayesian analysis. International Journal of Forecasting, 9, 95-108.

Ariño, M.A., \& Franses, P.H. (2000). Forecasting the levels of vector autoregressive log-transformed time series. International Journal of Forecasting, 16, 111-116.

Artis, M.J., \& Zhang, W. (1990). BVAR forecasts for the G-7. International Journal of Forecasting, 6, 349-362.

Ashley, R. (1988). On the relative worth of recent macroeconomic forecasts. International Journal of Forecasting, 4, 363-376.

Bhansali, R.J. (1996). Asymptotically efficient autoregressive model selection for multistep prediction. Annals of the Institute of Statistical Mathematics, 48, 577-602.

Bhansali, R.J. (1999). Autoregressive model selection for multistep prediction. Journal of Statistical Planning and Inference, 78, 295-305.

Bianchi, L., Jarrett, J., \& Hanumara, T.C. (1998), Improving forecasting for telemarketing centers by ARIMA modeling with interventions. International Journal of Forecasting, 14, 497-504.

Bidarkota, P.V. (1998). The comparative forecast performance of univariate and multivariate models: An application to real interest rate forecasting. International Journal of Forecasting, 14, 457-468.

Box, G.E.P., \& G.M. Jenkins (1970), Time Series Analysis: Forecasting and Control, San Francisco: Holden Day (revised ed. 1976).

Box, G.E.P., Jenkins, G.M., \& Reinsel, G.C. (1994). Time Series Analysis: Forecasting and Control, 3rd ed., Englewood Cliffs, NJ: Prentice Hall.

Chatfield, C. (1988). What is the 'best method of forecasting? Journal of Applied Statistics, 15, 19-38.

Chevillon, G., \& Hendry, D.F. (2005). Non-parametric direct multi-step estimation for forecasting economic processes. International Journal of Forecasting, 21, 201-218.

Cholette, P.A. (1982). Prior information and ARIMA forecasting. Journal of Forecasting, 1, $375-383$.

Cholette, P.A., \& Lamy, R. (1986). Multivariate ARIMA forecasting of irregular time series. International Journal of Forecasting, 2, 201-216.

Cummins, J.D., \& Griepentrog. G.L. (1985). Forecasting automobile insurance paid claims using econometric and ARIMA models. International Journal of Forecasting, 1, 203-215.

De Gooijer, J.G., \& Klein, A. (1991). On the cumulated multi-step-ahead predictions of vector autoregressive moving average processes. International Journal of Forecasting, 7, 501-513.

Dhrymes, P.J., \& Peristiani, S.C. (1988). A comparison of the forecasting performance of WEFA and ARIMA time series methods. International Journal of Forecasting, 4, 81-101.

Dhrymes, P.J., \& Thomakos, D. (1998). Structural VAR, MARMA and open economy models. International Journal of Forecasting, 14, 187-198.

Di Caprio, U., Genesio, R., Pozzi, S. \& Vicino, A. (1983). Short term load forecasting in electric power systems: A comparison of ARMA models and extended Wiener filtering. Journal of Forecasting, 2, 5976.

Downs, G.W., \& Rocke, D.M. (1983). Municipal budget forecasting with multivariate ARMA models. Journal of Forecasting, 2, 377-387.

Edlund, P-O. (1984). Identification of the multi-input Box-Jenkins transfer function model. Journal of Forecasting, 3, 297-308. 
Edlund, P-O., \& Karlsson, S. (1993). Forecasting the Swedish unemployment rate. VAR vs. transfer function modelling. International Journal of Forecasting, 9, 61-76.

Engle, R.F., \& Granger, C.W.J. (1987). Co-integration and error correction: Representation, estimation, and testing. Econometrica, 55, 1057-1072.

Funke, M. (1990). Assessing the forecasting accuracy of monthly vector autoregressive models: The case of five OECD countries. International Journal of Forecasting, 6, 363-378.

Geriner, P.T., \& Ord, J.K. (1991). Automatic forecasting using explanatory variables: A comparative study. International Journal of Forecasting, 7, 127-140.

Geurts, M.D., \& Kelly, J.P. (1986). Forecasting retail sales using alternative models. International Journal of Forecasting, 2, 261-272.

Geurts, M.D., \& Kelly, J.P. (1990). Comments on: “In defense of ARIMA modeling by D.J. Pack. International Journal of Forecasting, 6, 497-499.

Grambsch, P., \& Stahel, W.A. (1990). Forecasting demand for special telephone services: a case study. International Journal of Forecasting, 6, 53-64.

Guerrero, V.M. (1991). ARIMA forecasts with restrictions derived from a structural change. International Journal of Forecasting, 7, 339-347.

Gupta, S. (1987). Testing causality: Some caveats and a suggestion. International Journal of Forecasting, 3, 195-209.

Hafer, R.W., \& Sheehan, R.G. (1989). The sensitivity of VAR forecasts to alternative lag structures. International Journal of Forecasting, 5, 399-408.

Hansson, J., Jansson, P., \& Löf, M. (2005). Business survey data: Do they help in forecasting GDP growth? International Journal of Forecasting, 21, 377-389.

Harris, J.L., \& Liu, L-M. (1993). Dynamic structural analysis and forecasting of residential electricity consumption. International Journal of Forecasting, 9, 437-455.

Hein, S., \& Spudeck, R.E. (1988). Forecasting the daily federal funds rate. International Journal of Forecasting, 4, 581-591.

Heuts, R.M.J., \& Bronckers, J.H.J.M. (1988). Forecasting the Dutch heavy truck market: A multivariate approach. International Journal of Forecasting, 4, 57-59.

Hill, G., \& Fildes, R. (1984). The accuracy of extrapolation methods: An automatic Box-Jenkins package SIFT. Journal of Forecasting, 3, 319-323.

Hillmer, S.C., Larcker, D.F., \& Schroeder, D.A. (1983). Forecasting accounting data: A multiple timeseries analysis. Journal of Forecasting, 2, 389-404.

Holden, K., \& Broomhead, A. (1990). An examination of vector autoregressive forecasts for the U.K. economy. International Journal of Forecasting, 6, 11-23.

Hotta, L.K. (1993). The effect of additive outliers on the estimates from aggregated and disaggregated ARIMA models. International Journal of Forecasting, 9, 85-93.

Hotta, L.K., \& Cardoso Neto, J. (1993). The effect of aggregation on prediction in ARIMA models. Journal of Time Series Analysis, 14, 261-269.

Kang, I-B. (2003). Multi-period forecasting using different models for different horizons: an application to U.S. economic time series data. International Journal of Forecasting, 19, 387-400.

Karanasos, M. (2001). Prediction in ARMA models with GARCH in mean effects. Journal of Time Series Analysis, 22, 555-576.

Kim, J.H. (2003). Forecasting autoregressive time series with bias-corrected parameter estimators. International Journal of Forecasting, 19, 493-502.

Kling, J.L., \& Bessler, D.A. (1985). A comparison of multivariate forecasting procedures for economic time series. International Journal of Forecasting, 1, 5-24. 
Kolmogorov, A.N. (1941). Stationary sequences in Hilbert space (in Russian). Bull. Math. Univ. Moscow, 2, No. 6, 1941.

Koreisha, S.G. (1983). Causal implications: The linkage between time series and econometric modelling. Journal of Forecasting, 2, 151-168.

Krishnamurthi, L., Narayan, J. \& Raj, S.P. (1989). Intervention analysis using control series and exogenous variable in a transfer function model: A case study. International Journal of Forecasting, 5, 21-27.

Kunst, R., \& Neusser, K. (1986). A forecasting comparison of some VAR techniques. International Journal of Forecasting, 2, 447-456.

Landsman, W.R., \& Damodaran, A. (1989). A comparison of quarterly earnings per share forecast using James-Stein and unconditional least squares parameter estimators. International Journal of Forecasting, 5, 491-500.

Layton, A., Defris, L.V., \& Zehnwirth, B. (1986). An international comparison of economic leading indicators of telecommunication traffic. International Journal of Forecasting, 2, 413-425.

Ledolter, J. (1989). The effect of additive outliers on the forecasts from ARIMA models. International Journal of Forecasting, 5, 231-240.

Leone, R.P. (1987). Forecasting the effect of an environmental change on market performance: An intervention time-series. International Journal of Forecasting, 3, 463-478.

LeSage, J.P. (1989). Incorporating regional wage relations in local forecasting models with a Bayesian prior. International Journal of Forecasting, 5, 37-47.

LeSage, J.P., \& Magura, M. (1991). Using interindustry input-output relations as a Bayesian prior in employment forecasting models. International Journal of Forecasting, 7, 231-238.

Libert, G. (1984). The M-competition with a fully automatic Box-Jenkins procedure. Journal of Forecasting, 3, 325-328.

Lin, W.T. (1989). Modeling and forecasting hospital patient movements: Univariate and multiple time series approaches. International Journal of Forecasting, 5, 195-208.

Litterman, R.B. (1986). Forecasting with Bayesian vector autoregressions - Five years of experience. Journal of Business E Economic Statistics, 4, 25-38.

Liu, L-M., \& Lin, M-W. (1991). Forecasting residential consumption of natural gas using monthly and quarterly time series. International Journal of Forecasting, 7, 3-16.

Liu, T-R., Gerlow, M.E., \& Irwin, S.H. (1994). The performance of alternative VAR models in forecasting exchange rates. International Journal of Forecasting, 10, 419-433.

Lütkepohl, H. (1986). Comparison of predictors for temporally and contemporaneously aggregated time series. International Journal of Forecasting, 2, 461-475.

Makridakis, S., Andersen, A., Carbone, R., Fildes, R., Hibon, M., Lewandowski, R., Newton, J., Parzen, E., \& Winkler, R. (1982). The accuracy of extrapolation (time series) methods: results of a forecasting competition. Journal of Forecasting, 1, 111-153.

Meade, N. (2000). A note on the robust trend and ARARMA methodologies used in the M3 competition. International Journal of Forecasting, 16, 517-519.

Meade, N. (2002). A comparison of the accuracy of short term foreign exchange forecasting methods. International Journal of Forecasting, 18, 67-83.

Meade, N., \& Smith, I. (1985). ARARMA vs ARIMA - a study of the benefits of a new approach to forecasting. Omega, 13, 519-534.

Mélard, G., \& Pasteels, J-M. (2000). Automatic ARIMA modeling including interventions, using time series expert software. International Journal of Forecasting, 16, 497-508.

del Moral, M.J., \& Valderrama, M.J. (1997). A principal component approach to dynamic regression models. International Journal of Forecasting, 13, 237-244. 
Newbold, P. (1983). ARIMA model building and the time series analysis approach to forecasting. Journal of Forecasting, 2, 23-35.

Newbold, P., Agiakloglou, C., \& Miller, J. (1994). Adventures with ARIMA software. International Journal of Forecasting, 10, 573-581.

Öller, L-E. (1985). Macroeconomic forecasting with a vector ARIMA model. International Journal of Forecasting, 1, 143-150.

Pack, D.J. (1990). Rejoinder to: Comments on: "In defense of ARIMA modeling by M.D. Geurts and J.P. Kelly. International Journal of Forecasting, 6, 501-502.

Parzen, E. (1982). ARARMA models for time series analysis and forecasting. Journal of Forecasting, 1, 6782.

Peña, D., \& Sánchez, I. (2005). Multifold predictive validation in ARMAX time series models. Journal of the American Statistical Association, 100, 135-146.

Pflaumer, P. (1992). Forecasting US population totals with the Box-Jenkins approach. International Journal of Forecasting, 8, 329-338.

Poskitt, D.S. (2003). On the specification of cointegrated autoregressive moving-average forecasting systems. International Journal of Forecasting, 19, 503-519.

Poulos, L., Kvanli, A., \& Pavur, R. (1987). A comparison of the accuracy of the Box-Jenkins method with that of automated forecasting methods. International Journal of Forecasting, 3, 261-267.

du Preez, J., \& Witt, S.F. (2003). Univariate versus multivariate time series forecasting: An application to international tourism demand. International Journal of Forecasting, 19, 435-451.

Quenouille, M.H. (1957). The Analysis of Multiple Time-Series, London: Griffin. (2nd ed. 1968).

Ribeiro Ramos, F.F. (2003). Forecasts of market shares from VAR and BVAR models: A comparison of their accuracy. International Journal of Forecasting, 119, 95-110.

Reimers, H-E. (1997). Forecasting of seasonal cointegrated processes. International Journal of Forecasting, $13,369-380$.

Riise, T., \& Tjøstheim, D. (1984). Theory and practice of multivariate ARMA forecasting. Journal of Forecasting, 3, 309-317.

Shoesmith, G.L. (1992). Non-cointegration and causality: Implications for VAR modeling. International Journal of Forecasting, 8, 187-199.

Shoesmith, G.L. (1995). Multiple cointegrating vectors, error correction, and forecasting with Littermans model. International Journal of Forecasting, 11, 557-567.

Simkins, S. (1995). Forecasting with vector autoregressive (VAR) models subject to business cycle restrictions. International Journal of Forecasting, 11, 569-583.

Spencer, D.E. (1993). Developing a Bayesian vector autoregressive forecasting model. International Journal of Forecasting, 9, 407-421.

Tashman, L.J., \& Leach, M.L. (1991). ‘Automatic forecasting software: a survey and evaluation. International Journal of Forecasting, 7, 209-230.

Tashman, L.J. (2000). Out-of sample tests of forecasting accuracy: a tutorial and review. International Journal of Forecasting, 16, 437-450.

Tegene, A., \& Kuchler, F. (1994). Evaluating forecasting models of farmland prices. International Journal of Forecasting, 10, 65-80.

Texter, P.A., \& Ord, J.K. (1989). Forecasting using automatic identification procedures: A comparative analysis. International Journal of Forecasting, 5, 209-215.

Ullah, T.A. (1993). Forecasting of multivariate periodic autoregressive moving-average processes. Journal of Time Series Analysis, 14, 645-657. 
Villani, M. (2001). Bayesian prediction with cointegrated vector autoregression. International Journal of Forecasting, 17, 585-605.

Wall, K.D., \& Stoffer, D.S. (2002). A state space approach to bootstrapping conditional forecasts in ARMA models. Journal of Time Series Analysis, 23, 733-751.

Wang, Z., \& Bessler, D.A. (2004). Forecasting performance of multivariate time series models with a full and reduced rank: an empirical examination. International Journal of Forecasting, 20, 683-695.

Weller, B.R. (1989). National indicator series as quantitative predictors of small region monthly employment levels. International Journal of Forecasting, 5, 241-247.

West, K.D. (1996). Asymptotic inference about predictive ability. Econometrica, 68, 1097-1084.

Wieringa, J.E., \& Horváth, C. (2005). Computing level-impulse responses of log-specified VAR systems. International Journal of Forecasting, 21, 279-289.

Yule, G.U. (1927). On the method of investigating periodicities in disturbed series, with special reference to Wölfers sunspot numbers. Philosophical Transactions of the Royal Society London, Series A, 226, 267298.

Zellner, A. (1971). An Introduction to Bayesian Inference in Econometrics, New York: Wiley.

\section{Section 4. Seasonality}

Albertson, K., \& Aylen, J. (1996). Modelling the Great Lake freeze: Forecasting and seasonality in the market for ferrous scrap. International Journal of Forecasting, 12, 345-359.

Bunn, D.W., \& Vassilopoulos, A.I. (1993). Using group seasonal indices in multi-item short-term forecasting. International Journal of Forecasting, 9, 517-526.

Bunn, D.W., \& Vassilopoulos, A.I. (1999). Comparison of seasonal estimation methods in multi-item short-term forecasting. International Journal of Forecasting, 15, 431-443.

Chen, C. (1997). Robustness properties of some forecasting methods for seasonal time series: A Monte Carlo study. International Journal of Forecasting, 13, 269-280.

Clements, M.P., \& Hendry, D.F. (1997). An empirical study of seasonal unit roots in forecasting. International Journal of Forecasting, 13, 341-355.

Cleveland, R.B., Cleveland, W.S., McRae, J.E., \& Terpenning, I. (1990). STL: A seasonal-trend decomposition procedure based on Loess (with discussion). Journal of Official Statistics, 6, 3-73.

Dagum, E.B. (1982). Revisions of time varying seasonal filters. Journal of Forecasting, 1, 173-187.

Findley, D.F., Monsell, B.C., Bell, W.R., Otto, M.C., \& Chen, B.-C. (1998). New capabilities and methods of the X-12-ARIMA seasonal adjustment program. Journal of Business \& Economics Statistics, 16, 127152.

Findley, D.F., Wills, K.C., \& Monsell, B.C. (2004). Seasonal adjustment perspectives on “Damping seasonal factors: shrinkage estimators for the X-12-ARIMA program. International Journal of Forecasting, 20, 551-556.

Franses, P.H., \& Koehler, A.B. (1998). A model selection strategy for time series with increasing seasonal variation. International Journal of Forecasting, 14, 405-414.

Franses, P.H., \& Romijn, G. (1993). Periodic integration in quarterly UK macroeconomic variables. International Journal of Forecasting, 9, 467-476.

Franses, P.H., \& van Dijk, D. (2005). The forecasting performance of various models for seasonality and nonlinearity for quarterly industrial production. International Journal of Forecasting, 21, 87-102.

Gómez, V., \& Maravall, A. (2001). Seasonal adjustment and signal extraction in economic time series. Chapter 8 in A course in time series analysis, ed. D. Peña, G.C. Tiao and R.S. Tsay, John Wiley \& Sons: New York. 
Herwartz, H. (1997). Performance of periodic error correction models in forecasting consumption data. International Journal of Forecasting, 13, 421-431.

Huot, G., Chiu, K., \& Higginson, J. (1986). Analysis of revisions in the seasonal adjustment of data using X-11-ARIMA model-based filters. International Journal of Forecasting, 2, 217-229.

Hylleberg, S., \& Pagan, A.R. (1997). Seasonal integration and the evolving seasonals model. International Journal of Forecasting, 13, 329-340.

Hyndman, R.J. (2004). The interaction between trend and seasonality. International Journal of Forecasting, 20, 561-563.

Kaiser, R., \& Maravall, A. (2005). Combining filter design with model-based filtering (with an application to business-cycle estimation). International Journal of Forecasting, 21, 691-710.

Koehler, A.B. (2004). Comments on damped seasonal factors and decisions by potential users. International Journal of Forecasting, 20, 565-566.

Kulendran, N., \& King, M.L. (1997). Forecasting international quarterly tourist flows using errorcorrection and time-series models. International Journal of Forecasting, 13, 319-327.

Ladiray, D., \& Quenneville, B. (2004). Implementation issues on shrinkage estimators for seasonal factors within the X-11 seasonal adjustment method. International Journal of Forecasting, 20, 557-560.

Miller, D.M., \& Williams, D. (2003). Shrinkage estimators of time series seasonal factors and their effect on forecasting accuracy. International Journal of Forecasting, 19, 669-684.

Miller, D.M., \& Williams, D. (2004). Damping seasonal factors: Shrinkage estimators for seasonal factors within the X-11 seasonal adjustment method (with commentary). International Journal of Forecasting, 20, 529-550.

Noakes, D.J., McLeod, A.I. \& Hipel, K.W. (1985). Forecasting monthly riverflow time series. International Journal of Forecasting, 1, 179-190.

Novales, A., \& de Fruto, R.F. (1997). Forecasting with time periodic models: A comparison with time invariant coefficient models. International Journal of Forecasting, 13, 393-405.

Ord, J.K. (2004). Shrinking: when and how? International Journal of Forecasting, 20, 567-568.

Osborn, D. (1990). A survey of seasonality in UK macroeconomic variables. International Journal of Forecasting, 6, 327-336.

Paap, R., Franses, P.H., \& Hoek, H. (1997). Mean shifts, unit roots and forecasting seasonal time series. International Journal of Forecasting, 13, 357-368.

Pfeffermann, D., Morry, M., \& Wong, P. (1995). Estimation of the variances of X-11 ARIMA seasonally adjusted estimators for a multiplicative decomposition and heteroscedastic variances. International Journal of Forecasting, 11, 271-283.

Quenneville, B., Ladiray, D., \& Lefrançois, B. (2003). A note on Musgrave asymmetrical trend-cycle filters. International Journal of Forecasting, 19, 727-734.

Simmons, L.F. (1990). Time-series decomposition using the sinusoidal model. International Journal of Forecasting, 6, 485-495.

Taylor, A.M.R. (1997). On the practical problems of computing seasonal unit root tests. International Journal of Forecasting, 13, 307-318.

Wells, J.M. (1997). Modelling seasonal patterns and long-run trends in U.S. time series. International Journal of Forecasting, 13, 407-420.

Withycombe, R. (1989). Forecasting with combined seasonal indices. International Journal of Forecasting, $5,547-552$. 


\section{Section 5. State space and structural models and the Kalman filter}

Coomes, P.A. (1992). A Kalman filter formulation for noisy regional job data. International Journal of Forecasting, 7, 473-481.

Grunwald, G.K., Hamza, K., \& Hyndman, R.J. (1997). Some properties and generalizations of nonnegative Bayesian time series models. Journal of the Royal Statistical Society (B), 59, 615-626.

Grunwald, G.K., Raftery, A.E., \& Guttorp, P. (1993). Time series of continuous proportions. Journal of the Royal Statistical Society (B), 55, 103-116.

Harrison, P.J., \& Stevens, C.F. (1976). Bayesian forecasting. Journal of the Royal Statistical Society (B), $38,205-247$.

Harvey, A.C. (1984). A unified view of statistical forecasting procedures (with discussion). Journal of Forecasting, 3, 245-283.

Harvey, A.C. (1989). Forecasting, Structural Time Series Models and the Kalman Filter, Cambridge: Cambridge University Press.

Harvey, A.C. (2006). Forecasting with unobserved component time series models. In Elliot, G., C.W.J. Granger \& A. Timmermann (eds.). Handbook of Economic Forecasting, Amsterdam: Elsevier Science.

Harvey, A.C., \& Fernandes, C. (1989). Time series models for count or qualitative observations. Journal of Business E Economic Statistics, 7, 407-422.

Harvey, A.C., \& Snyder. R.D. (1990). Structural time series models in inventory control. International Journal of Forecasting, 6, 187-198.

Kalman, R.E. (1960). A new approach to linear filtering and prediction problems. Transaction of the ASME - Journal of Basic Engineering, 82D, 35-45.

Mittnik, S. (1990). Macroeconomic forecasting experience with balanced state space models. International Journal of Forecasting, 6, 337-345.

Patterson, K.D. (1995). Forecasting the final vintage of real personal disposable income: A state space approach. International Journal of Forecasting, 11, 395-405.

Proietti, T. (2000). Comparing seasonal components for structural time series models. International Journal of Forecasting, 16, 247-260.

Ray, W.D. (1989). Rates of convergence to steady state for the linear growth version of a dynamic linear model (DLM). International Journal of Forecasting, 5, 537-545.

Schweppe, F. (1965). Evaluation of likelihood functions for Gaussian signals. IEEE Transactions on Information Theory, 11(1), 61-70.

Shumway, R.H., \& Stoffer, D.S. (1982). An approach to time series smoothing and forecasting using the EM algorithm. Journal of Time Series Analysis, 3, 253-264.

Smith, J.Q. (1979). A generalization of the Bayesian steady forecasting model. Journal of the Royal Statistical Society, Series B, 41, 375-387.

Vinod, H.D., \& Basu, P. (1995). Forecasting consumption, income and real interest rates from alternative state space models. International Journal of Forecasting, 11, 217-231.

West, M., \& Harrison, P.J. (1989). Bayesian Forecasting and Dynamic Models, Springer-Verlag, New York. (2nd ed., 1997).

West, M., Harrison, P.J., \& Migon, H.S. (1985). Dynamic generalized linear models and Bayesian forecasting (with discussion). Journal of the American Statistical Association, 80, 73-83. 


\section{Section 6. Nonlinear}

Adya, M., \& Collopy, F. (1998). How effective are neural networks at forecasting and prediction? A review and evaluation. Journal of Forecasting, 17, 481-495.

Al-Qassem, M.S., \& Lane, J.A. (1989). Forecasting exponential autoregressive models of order 1. Journal of Time Series Analysis, 10, 95-113.

Astatkie, T., Watts, D.G., \& Watt, W.E. (1997). Nested threshold autoregressive (NeTAR) models. International Journal of Forecasting, 13, 105-116.

Balkin, S.D., \& Ord, J.K. (2000). Automatic neural network modeling for univariate time series. International Journal of Forecasting, 16, 509-515.

Bradley, M.D., \& Jansen, D.W. (2004). Forecasting with a nonlinear dynamic model of stock returns and industrial production. International Journal of Forecasting, 20, 321-342.

Boero, G., \& Marrocu, E. (2004). The performance of SETAR models: A regime conditional evaluation of point, interval and density forecasts. International Journal of Forecasting, 20, 305-320.

Brockwell, P.J., \& Hyndman, R.J. (1992). 'On continuous-time threshold autoregression. International Journal of Forecasting, 8, 157-173.

Cai, Z., Fan, J. \& Yao, Q. (2000). Functional-coefficient regression models for nonlinear time series. Journal of the American Statistical Association, 95, 941-956.

Callen, J.F., Kwan, C.C.Y., Yip, P.C.Y., \& Yuan, Y. (1996). Neural network forecasting of quarterly accounting earnings. International Journal of Forecasting, 12, 475-482.

Cao, L \& Soofi, A.S. (1999). Nonlinear deterministic forecasting of daily dollar exchange rates. International Journal of Forecasting, 15, 421-430.

Casdagli, M. (1992). Chaos and deterministic versus stochastic non-linear modelling. Journal of the Royal Statistical Society, Series B, 55, 303-328.

Cecen, A.A., \& Erkal, C. (1996). Distinguishing between stochastic and deterministic behavior in high frequency foreign rate returns: Can non-linear dynamics help forecasting. International Journal of Forecasting, 12, 465-473.

Chatfield, C. (1993). Neural network: forecasting breakthrough or passing fad? International Journal of Forecasting, 9, 1-3.

Chatfield, C. (1995). Positive or negative. International Journal of Forecasting, 11, 501-502.

Church, K.B., \& Curram, S.P. (1996). Forecasting consumers expenditure: A comparison between econometric and neural network models. International Journal of Forecasting, 12, 255-267.

Clements, M.P., \& Smith, J. (1997). The performance of alternative methods for SETAR models. International Journal of Forecasting, 13, 463-475.

Clements, M.P., Franses, P.H., \& Swanson, N.R. (2004). Forecasting economic and financial time-series with non-linear models. International Journal of Forecasting, 20, 169-183.

Conejo, A.J., Contreras, J., Espínola, R., \& Plazas, M.A. (2005). Forecasting electricity prices for a dayahead pool-based electricity market. International Journal of Forecasting, 21, 435-462.

Dahl, C.M., \& Hylleberg, S. (2004). Flexible regression models and relative forecast performance. International Journal of Forecasting, 20, 201-217.

Darbellay, G.A., \& Slama, M. (2000). Forecasting the short-term demand for electricity: Do neural networks stand a better chance? International Journal of Forecasting, 16, 71-83.

De Gooijer, J.G., \& Kumar, V. (1992). Some recent developments in non-linear time series modelling, testing and forecasting. International Journal of Forecasting, 8, 135-156.

De Gooijer, J.G., \& Vidiella-i-Anguera, A. (2004). Forecasting threshold cointegrated systems. International Journal of Forecasting, 20, 237-253. 
Enders, W., \& Falk, B. (1998). Threshold-autoregressive, median-unbiased, and cointegration tests of purchasing power parity. International Journal of Forecasting, 14, 171-186.

Fernández-Rodríguez, F., Sosvilla-Rivero, S., \& Andrada-Félix, J. (1999). Exchange-rate forecasts with simultaneous nearest-neighbour methods; evidence from the EMS. International Journal of Forecasting, $15,383-392$.

Fok, D.F., van Dijk, D., \& Franses, P.H. (2005). Forecasting aggregated using panels of nonlinear time series. International Journal of Forecasting, 21, 785-794.

Franses, P.H., Paap, R. \& Vroomen, B. (2004). Forecasting unemployment using an autoregression with censored latent effects parameters. International Journal of Forecasting, 20, 255-271.

Ghiassi, M., Saidane, H., \& Zimbra, D.K. (2005). A dynamic artificial neural network model for forecasting series events. International Journal of Forecasting, 21, 341-362.

Gorr, W. (1994). Research prospective on neural network forecasting. International Journal of Forecasting, $10,1-4$.

Gorr, W., Nagin, D., \& Szczypula, J. (1994). Comparative study of artificial neural network and statistical models for predicting student grade point averages. International Journal of Forecasting, 10, 17-34.

Granger, C.W.J., \& Teräsvirta, T. (1993). Modelling Nonlinear Economic Relationships, Oxford: Oxford University Press.

Hamilton, J.D. (2001). A parametric approach to flexible nonlinear inference. Econometrica, 69, 537-573.

Harvill, J.L., \& Ray, B.K. (2005). A note on multi-step forecasting with functional coefficient autoregressive models. International Journal of Forecasting, 21, 717-727.

Hastie, T.J., \& Tibshirani, R.J. (1991). Generalized Additive Models, London: Chapman and Hall.

Heravi, S., Osborn, D.R., \& Birchenhall, C.R. (2004). Linear versus neural network forecasting for European industrial production series. International Journal of Forecasting, 20, 435-446.

Herwartz, H. (2001). Investigating the JPY/DEM-rate: arbitrage opportunities and a case for asymmetry. International Journal of Forecasting, 17, 231-245.

Hill, T., Marquez, L., OConnor, M., \& Remus, W. (1994). Artificial neural network models for forecasting and decision making. International Journal of Forecasting, 10, 5-15.

Hippert, H.S., Pedreira, C.E., \& Souza, R.C. (2001). Neural networks for short-term load forecasting: A review and evaluation. IEEE Transactions on Power Systems, 16, 44-55.

Hippert, H.S., Bunn, D.W., \& Souza, R.C. (2005). Large neural networks for electricity load forecasting: Are they overfitted? International Journal of Forecasting, 21, 425-434.

Lisi, F., \& Medio, A. (1997). Is a random walk the best exchange rate predictor? International Journal of Forecasting, 13, 255-267.

Ludlow, J., \& Enders, W. (2000). Estimating non-linear ARMA models using Fourier coefficients. International Journal of Forecasting, 16, 333-347.

Marcellino, M. (2004). Forecasting EMU macroeconomic variables. International Journal of Forecasting, $20,359-372$.

Olson, D., \& Mossman, C. (2003). Neural network forecasts of Canadian stock returns using accounting ratios. International Journal of Forecasting, 19, 453-465.

Pemberton, J. (1987). Exact least squares multi-step prediction from nonlinear autoregressive models. Journal of Time Series Analysis, 8, 443-448.

Poskitt, D.S., \& Tremayne, A.R. (1986). The selection and use of linear and bilinear time series models. International Journal of Forecasting, 2, 101-114.

Qi, M. (2001). Predicting US recessions with leading indicators via neural network models. International Journal of Forecasting, 17, 383-401. 
Sarantis, N. (2001). Nonlinearities, cyclical behaviour and predictability in stock markets: International evidence. International Journal of Forecasting, 17, 459-482.

Swanson, N.R., \& White, H. (1997). Forecasting economic time series using flexible versus fixed specification and linear versus nonlinear econometric models. International Journal of Forecasting, 13, 439-461.

Teräsvirta, T. (2006). Forecasting economic variables with nonlinear models. In Elliot, G., C.W.J. Granger \& A. Timmermann (eds.). Handbook of Economic Forecasting, Amsterdam: Elsevier Science.

Teräsvirta, T., van Dijk, D., \& Medeiros, M.C. (2005). Linear models, smooth transition autoregressions, and neural networks for forecasting macroeconomic time series: A re-examination. International Journal of Forecasting, 21, 755-774.

Tkacz, G. (2001). Neural network forecasting of Canadian GDP growth. International Journal of Forecasting, 17, 57-69.

Tong, H. (1983). Threshold Models in Non-linear Time Series Analysis, New York: Springer-Verlag.

Tong, H. (1990) Non-linear Time Series: A Dynamical System Approach, Oxford: Clarendon Press.

Volterra, V. (1930). Theory of Functionals and of Integro-differential Equations, Dover, New York.

Wiener, N. (1958). Non-linear Problems in Random Theory, London: Wiley.

Zhang, G., Patuwo, B.E., \& Hu, M.Y. (1998). Forecasting with artificial networks: The state of the art. International Journal of Forecasting, 14, 35-62.

\section{Section 7. Long memory}

Andersson, M.K. (2000). Do long-memory models have long memory? International Journal of Forecasting, $16,121-124$.

Baillie, R.T., \& Chung, S-K. (2002). Modeling and forecasting from trend-stationary long memory models with applications to climatology. International Journal of Forecasting, 18, 215-226.

Beran, J., Feng, Y., Ghosh, S., \& Sibbertsen, P. (2002). On robust local polynomial estimation with longmemory errors. International Journal of Forecasting, 18, 227-241.

Bhansali, R.J., \& Kokoszka, P.S. (2002). Computation of the forecast coefficients for multistep prediction of long-range dependent time series. International Journal of Forecasting, 18, 181-206.

Franses, P.H., \& Ooms, M. (1997). A periodic long-memory model for quarterly UK inflation. International Journal of Forecasting, 13, 117-126.

Granger, C.W.J., \& Joyeux, R. (1980). An introduction to long memory time series models and fractional differencing. Journal of Time Series Analysis, 1, 15-29.

Hurvich, C.M. (2002). Multistep forecasting of long memory series using fractional exponential models. International Journal of Forecasting, 18, 167-179.

Man, K.S. (2003). Long memory time series and short term forecasts. International Journal of Forecasting, $19,477-491$.

Öller, L-E. (1985). How far can changes in general business activity be forecasted? International Journal of Forecasting, 1, 135-141.

Ramjee, R., Crato, N., \& Ray, B.K. (2002). A note on moving average forecasts of long memory processes with an application to quality control. International Journal of Forecasting, 18, 291-297.

Ravishanker, N., \& Ray, B.K. (2002). Bayesian prediction for vector ARFIMA processes. International Journal of Forecasting, 18, 207-214.

Ray, B.K. (1993). Long-range forecasting of IBM product revenues using a seasonal fractionally differenced ARMA model. International Journal of Forecasting, 9, 255-269.

Ray, B.K. (1993). Modeling long-memory processes for optimal long-range prediction. Journal of Time Series Analysis, 14, 511-525. 
Smith, J., \& Yadav, S. (1994). Forecasting costs incurred from unit differencing fractionally integrated processes. International Journal of Forecasting, 10, 507-514.

Souza, L.R., \& Smith, J. (2002). Bias in the memory for different sampling rates. International Journal of Forecasting, 18, 299-313.

Souza, L.R., \& Smith, J. (2004). Effects of temporal aggregation on estimates and forecasts of fractionally integrated processes: A Monte-Carlo study. International Journal of Forecasting, 20, 487-502.

\section{Section 8. ARCH/GARCH}

Awartani, B.M.A., \& Corradi, V. (2005). Predicting the volatility of the S\&P-500 stock index via GARCH models: the role of asymmetries. International Journal of Forecasting, 21, 167-183.

Baillie, R.T., Bollerslev, T., \& Mikkelsen, H.O. (1996). Fractionally integrated generalized autoregressive conditional heteroskedasticity. Journal of Econometrics, 74, 3-30.

Bera, A., \& Higgins, M. (1993). ARCH models: properties, estimation and testing. Journal of Economic Surveys, 7, 305-365.

Bollerslev, T., \& Wright, J.H. (2001). High-frequency data, frequency domain inference, and volatility forecasting. Review of Economic and Statistics, 83, 596-602.

Bollerslev, T., Chou, R.Y., \& Kroner, K.F. (1992). ARCH modeling in finance: a review of the theory and empirical evidence. Journal of Econometrics, 52, 5-59.

Bollerslev, T., Engle, R.F., \& Nelson, D.B. (1994). ARCH models. in Handbook of Econometrics, Vol. IV, eds. R.F. Engle and D.L. McFadden, Amsterdam: North-Holland, pp. 2959-3038.

Brooks, C. (1998). Predicting stock index volatility: Can market volume help? Journal of Forecasting, $17,59-80$.

Brooks, C., Burke, S.P., \& Persand, G. (2001). Benchmarks and the accuracy of GARCH model estimation. International Journal of Forecasting, 17, 45-56.

Doidge, C., \& Wei, J.Z. (1998). Volatitility forecasting and the efficiency of the Toronto 35 index options market. Canadian Journal of Administrative Sciences, 15, 28-38.

Engle, R.F. (1982). Autoregressive conditional heteroscedasticity with estimates of the variance of the United Kingdom inflation. Econometrica, 50, 987-1008.

Engle, R.F. (2002). New frontiers for ARCH models. Manuscript prepared for the conference "Modeling and Forecasting Financial Volatility (Perth, Australia, 2001). Available at http:/ / pages.stern.nyu.edu / rengle.

Engle, R.F., \& Ng, V. (1993). Measuring and testing the impact of news on volatility. Journal of Finance, $48,1749-1778$.

Franses, P.H., \& Ghijsels, H. (1999). Additive outliers, GARCH and forecasting volatility. International Journal of Forecasting, 15, 1-9.

Galbraith, J.W., \& Kisinbay, T. (2005). Content horizons for conditional variance forecasts. International Journal of Forecasting, 21, 249-260.

Granger, C.W.J. (2002). Long memory, volatility, risk and distribution. Manuscript, University of California, San Diego. Available at http:/ / www.cass.city.ac.uk/conferences/esrc2002/Granger.pdf

Hentschel, L. (1995). All in the family: nesting symmetric and asymmetric GARCH models. Journal of Financial Economics, 39, 71-104.

Kroner, K.F., Kneafsey, K.P., \& Claessens, S. (1995). Forecasting volatility in commodity markets. Journal of Forecasting, 14, 77-95.

Pagan, A. (1996). The econometrics of financial markets. Journal of Empirical Finance, 3, 15-102.

Poon, S-H., \& Granger, C.W.J. (2003). Forecasting volatility in financial markets: a review. Journal of 
Economic Literature, 41, 478-539.

Poon, S-H., \& Granger, C.W.J. (2005). Practical issues in forecasting volatility. Financial Analysts Journal, 61, 45-56.

Sabbatini, M., \& Linton, O. (1998). A GARCH model of the implied volatility of the Swiss market index from option prices. International Journal of Forecasting, 14, 199-213.

Taylor, S.J. (1987). Forecasting the volati lity of currency exchange rates. International Journal of Forecasting, 3, 159-170.

Vasilellis, G.A., \& Meade, N. (1996). Forecasting volatility for portfolio selection. Journal of Business Finance \& Accounting, 23, 125-143.

\section{Section 9. Count data forecasting}

Brännäs, K. (1995). Prediction and control for a time-series count data model. International Journal of Forecasting, 11, 263-270.

Brännäs, K., Hellström, J., \& Nordström, J. (2002). A new approach to modelling and forecasting monthly guest nights in hotels. International Journal of Forecasting, 18, 19-30.

Croston, J.D. (1972). Forecasting and stock control for intermittent demands. Operational Research Quarterly, 23, 289-303.

Diebold, F.X., Gunther, T.A., \& Tay, A.S. (1998). Evaluating density forecasts, with applications to financial risk management. International Economic Review, 39, 863-883.

Freeland, R.K., \& McCabe, B.P.M. (2004). Forecasting discrete valued low count time series. International Journal of Forecasting, 20, 427-434.

Grunwald, G.K., Hyndman, R.J., Tedesco, L.M., \& Tweedie, R.L. (2000). Non-Gaussian conditional linear AR(1) models. Australian and New Zealand Journal of Statistics, 42, 479-495.

Diggle, P.J., Heagerty, P., Liang, K.-Y., \& Zeger, S. (2002). Analysis of longitudinal data, 2nd ed., Oxford University Press: Oxford.

Johnston, F.R., \& Boylan, J.E. (1996). Forecasting intermittent demand: a comparative evaluation of Crostons method. International Journal of Forecasting, 12, 297-298.

McCabe, B.P.M. \& Martin, G.M. (2005). Bayesian predictions of low count time series. International Journal of Forecasting, 21, 315-330.

Syntetos, A.A., \& Boylan, J.E. (2005). The accuracy of intermittent demand estimates. International Journal of Forecasting, 21, 303-314.

Willemain, T.R., Smart, C.N., Shockor, J.H., \& DeSautels, P.A. (1994). Forecasting intermittent demand in manufacturing: a comparative evaluation of Crostons method. International Journal of Forecasting, $10,529-538$.

Willemain, T.R., Smart, C.N., \& Schwarz, H.F. (2004). A new approach to forecasting intermittent demand for service parts inventories. International Journal of Forecasting, 20, 375-387.

\section{Section 10. Forecast evaluation and accuracy measures}

Ahlburg, D.A., Chatfield, C., Taylor, S.J., Thompson, P.A., Winkler, R.L., Murphy, A.H., Collopy, F., \& Fildes, R. (1992). A commentary on error measures. International Journal of Forecasting, 8, 99-111.

Armstrong, J.S., \& Collopy, F. (1992). Error measures for generalizing about forecasting methods: Empirical comparisons. International Journal of Forecasting, 8, 69-80.

Chatfield, C. (1988). Editorial: Apples, oranges and mean square error. International Journal of Forecasting, $4,515-518$.

Clements, M.P., \& Hendry, D.F. (1993). On the limitations of comparing mean square forecast errors. 
Journal of Forecasting, 12, 617-637.

Diebold, F.X., \& R.S. Mariano (1995). 'Comparing Predictive Accuracy. Journal of Business \& Economic Statistics, 13, 253-263.

Fildes, R., \& Makridakis, S. (1988). Forecasting and loss functions. International Journal of Forecasting, $4,545-550$.

Fildes, R. (1992). The evaluation of extrapolative forecasting methods. International Journal of Forecasting, 8, 81-98.

Fildes, R., Hibon, M., Makridakis, S., \& Meade, N. (1998). Generalising about univariate forecasting methods: further empirical evidence. International Journal of Forecasting, 14, 339-358.

Flores, B. (1989). The utilization of the Wilcoxon test to compare forecasting methods: A note. International Journal of Forecasting, 5, 529-535.

Goodwin, P., \& Lawton, R. (1999). On the asymmetry of the symmetric MAPE. International Journal of Forecasting, 15, 405-408.

Granger, C.W.J., \& Jeon, Y. (2003a). A time-distance criterion for evaluating forecasting models. International Journal of Forecasting, 19, 199-215.

Granger, C.W.J., \& Jeon, Y. (2003b). Comparing forecasts of inflation using time distance. International Journal of Forecasting, 19, 339-349. (Corrigendum: Vol 19:4, p. 767).

Harvey, D., Leybourne, S., \& Newbold, P. (1997). Testing the equality of prediction mean squared errors. International Journal of Forecasting, 13, 281-291.

Koehler, A.B. (2001). The asymmetry of the sAPE measure and other comments on the M3-Competition. International Journal of Forecasting, 17, 570-574.

Mahmoud, E. (1984). Accuracy in forecasting: A survey. Journal of Forecasting, 3, 139-159.

Makridakis, S., Andersen, A., Carbone, R., Fildes, R.. Hibon, M., Lewandowski, R., Newton, J., Parzen, E., \& Winkler, R. (1982). The accuracy of extrapolation (time series) methods: results of a forecasting competition. Journal of Forecasting, 1, 111-153.

Makridakis, S. (1993). Accuracy measures: theoretical and practical concerns. International Journal of Forecasting, 9, 527-529.

Makridakis, S., \& Hibon, M. (2000). The M3-Competition: results, conclusions and implications. International Journal of Forecasting, 16, 451-476.

Makridakis, S., Wheelwright, S.C., \& Hyndman, R.J. (1998). Forecasting: methods and applications, 3rd ed., John Wiley \& Sons: New York.

McCracken, M.W. (2004). Parameter estimation and tests of equal forecast accuracy between non-nested models. International Journal of Forecasting, 20, 503-514.

Sullivan, R., Timmermann, A., \& White, H. (2003). Forecast evaluation with shared data sets. International Journal of Forecasting, 19, 217-227.

Theil, H. (1966). Applied Economic Forecasting, North-Holland: Amsterdam.

Thompson, P.A. (1990). An MSE statistic for comparing forecast accuracy across series. International Journal of Forecasting, 6, 219-227.

Thompson, P.A. (1991). Evaluation of the M-competition forecasts via log mean squared error ratio. International Journal of Forecasting, 7, 331-334.

Wun, L-M., \& Pearn, W.L. (1991). Assessing the statistical characteristics of the mean absolute error of forecasting. International Journal of Forecasting, 7, 335-337. 


\section{Section 11. Combining}

Aksu, C., \& Gunter, S. (1992). An empirical analysis of the accuracy of SA, OLS, ERLS and NRLS combination forecasts. International Journal of Forecasting, 8, 27-43.

Bates, J.M., \& Granger, C.W.J. (1969). Combination of forecasts. Operations Research Quarterly, 20, 451468.

Bunn, D.W. (1985). Statistical efficiency in the linear combination of forecasts. International Journal of Forecasting, 1, 151-163.

Clemen, R.T. (1986). Linear constraints and the efficiency of combined forecasts. Journal of Forecasting, 6, 31-38.

Clemen, R.T. (1989). Combining forecasts: A review and annotated biography (with discussion) International Journal of Forecasting, 5, 559-583.

Deutsch, M., Granger, C.W.J., \& Teräsvirta, T. (1994). The combination of forecasts using changing weights. International Journal of Forecasting, 10, 47-57.

Diebold, F.X., \& Pauly, P. (1990). The use of prior information in forecast combination. International Journal of Forecasting, 6, 503-508.

Fang, Y. (2003). Forecasting combination and encompassing tests. International Journal of Forecasting, $19,87-94$.

Fiordaliso, A. (1998). A nonlinear forecast combination method based on Takagi-Sugeno fuzzy systems. International Journal of Forecasting, 14, 367-379.

Granger, C.W.J. (1989). Combining forecasts — twenty years later. Journal of Forecasting, 8, 167-173.

Granger, C.W.J., \& Ramanathan, R. (1984). Improved methods of combining forecasts. Journal of Forecasting, 3, 197-204.

Gunter, S.I. (1992). Nonnegativity restricted least squares combinations. International Journal of Forecasting, 8, 45-59.

Hendry, D.F., \& Clements, M.P. (2002). Pooling of forecasts. Econometrics Journal, 5, 1-31.

Hibon, M., \& Evgeniou, T. (2005). To combine or not to combine: selecting among forecasts and their combinations. International Journal of Forecasting, 21, 15-24.

Kamstra, M., \& Kennedy, P. (1998). Combining qualitative forecasts using logit. International Journal of Forecasting, 14, 83-93.

de Menezes, L.M., \& Bunn, D.W. (1998). The persistence of specification problems in the distribution of combined forecast errors. International Journal of Forecasting, 14, 415-426.

Miller, S.M., Clemen, R.T., \& Winkler, R.L. (1992). The effect of nonstationarity on combined forecasts. International Journal of Forecasting, 7, 515-529.

Newbold, P., \& Granger, C.W.J. (1974). Experience with forecasting univariate time series and the combination of forecasts. Journal of the Royal Statistical Society (A), 137, 131-165.

Taylor, J.W., \& Bunn, D.W. (1999). Investigating improvements in the accuracy of prediction intervals for combinations of forecasts: A simulation study. International Journal of Forecasting, 15, 325-339.

Terui, N., \& van Dijk, H.K. (2002). Combined forecasts from linear and nonlinear time series models. International Journal of Forecasting, 18, 421-438.

Winkler, R.L., \& Makridakis, S. (1983). ' The combination of forecasts. Journal of the Royal Statistical Society $(A), 146,150-157$.

Zou, H., \& Yang, Y. (2004). Combining time series models for forecasting. International Journal of Forecasting, 20, 69-84. 


\section{Section 12. Prediction intervals and densities}

Chatfield, C. (1993). Calculating interval forecasts. Journal of Business E Economic Statistics, 11, 121-135.

Chatfield, C., \& Koehler, A.B. (1991). On confusing lead time demand with $h$-period-ahead forecasts. International Journal of Forecasting, 7, 239-240.

Clements, M.P., \& Smith, J. (2002). Evaluating multivariate forecast densities: A comparison of two approaches. International Journal of Forecasting, 18, 397-407.

Clements, M.P., \& Taylor, N. (2001). Bootstrapping prediction intervals for autoregressive models. International Journal of Forecasting, 17, 247-267.

Diebold, F.X., Gunther, T.A., \& Tay, A.S. (1998). Evaluating density forecasts with applications to financial risk management. International Economic Review, 39, 863-883.

Diebold, F.X., Hahn, J.Y., \& Tay, A.S. (1999). Multivariate density forecast evaluation and calibration in financial risk management: high-frequency returns in foreign exchange. Review of Economics and Statistics, 81, 661-673.

Grigoletto, M. (1998). Bootstrap prediction intervals for autoregressions: Some alternatives. International Journal of Forecasting, 14, 447-456.

Hyndman, R.J. (1995). Highest density forecast regions for non-linear and non-normal time series models. Journal of Forecasting, 14, 431-441.

Kim, J.A. (1999). Asymptotic and bootstrap prediction regions for vector autoregression. International Journal of Forecasting, 15, 393-403.

Kim, J.A. (2004a). Bias-corrected bootstrap prediction regions for vector autoregression. Journal of Forecasting, 23, 141-154.

Kim, J.A. (2004b). Bootstrap prediction intervals for autoregression using asymptotically mean-unbiased estimators. International Journal of Forecasting, 20, 85-97.

Koehler, A.B. (1990). An inappropriate prediction interval. International Journal of Forecasting, 6, 557-558.

Lam, J.-P., \& Veall, M.R. (2002). Bootstrap prediction intervals for single period regression forecasts. International Journal of Forecasting, 18, 125-130.

Lefrançois, P. (1989). Confidence intervals for non-stationary forecast errors: Some empirical results for the series in the M-competition. International Journal of Forecasting, 5, 553-557.

Makridakis, S., \& Hibon, M. (1987). Confidence intervals: an empirical investigation of the series in the M-competition. International Journal of Forecasting, 3, 489-508.

Masarotto, G. (1990). Bootstrap prediction intervals for autoregressions. International Journal of Forecasting, 6, 229-239.

McCullough, B.D. (1994). Bootstrapping forecast intervals: An application to AR(p) models. Journal of Forecasting, 13, 51-66.

McCullough, B.D. (1996). Consistent forecast intervals when the forecast-period exogenous variables are stochastic. Journal of Forecasting, 15, 293-304.

Pascual, L., Romo, J., \& Ruiz, E. (2001). Effects of parameter estimation on prediction densities: A bootstrap approach. International Journal of Forecasting, 17, 83-103.

Pascual, L., Romo, J., \& Ruiz, E. (2004). Bootstrap predictive inference for ARIMA processes. Journal of Time Series Analysis, 25, 449-465.

Pascual, L., Romo, J., \& Ruiz, E. (2005). Bootstrap prediction intervals for power-transformed time series. International Journal of Forecasting, 21, 219-236.

Reeves, J.J. (2005). Bootstrap prediction intervals for ARCH models. International Journal of Forecasting, 21, 237-248.

Tay, A.S., \& Wallis, K.F. (2000). Density forecasting: a survey. Journal of Forecasting, 19, $235-254$. 
Reprinted in Clements, M.P., and Hendry, D.F. (eds.). A Companion to Economic Forecasting, pp. 4568. Oxford: Blackwell (2002).

Taylor, J.W., \& Bunn, D.W. (1999). Investigating improvements in the accuracy of prediction intervals for combinations of forecasts: A simulation study. International Journal of Forecasting, 15, 325-339.

Wallis, K.F. (1999). Asymmetric density forecasts of inflation and the Bank of Englands fan chart. National Institute Economic Review, 167, 106-112.

Wallis, K.F. (2003). Chi-squared tests of interval and density forecasts, and the Bank of Englands fan charts. International Journal of Forecasting, 19, 165-175.

\section{Section 13. A look to the future}

Armstrong, J.S. (2001). Suggestions for further research. www.forecastingprinciples.com/ researchers.html.

Andersen, T.G., Bollerslev, T., Diebold, F.X., \& Labys, P. (2003). Modeling and forecasting realized volatility. Econometrica, 71, 579-625.

Casella, G. (Editor) et al. (2000). Vignettes for the Year 2000. Journal of the American Statistical Association, 95, 1269-1368 (with 22 thought-provoking contributions).

Chatfield, C. (1988). The future of time-series forecasting. International Journal of Forecasting, 4, 411-419.

Chatfield, C. (1997). Forecasting in the 1990s. The Statistician, 46, 461-473.

Clements, M.P. (2003). Editorial: Some possible directions for future research. International Journal of Forecasting, 19, 1-3.

Cogger, K.C. (1988). Proposals for research in time series forecasting. International Journal of Forecasting, $4,403-410$.

Dawes, R., Fildes, R., Lawrence, M., \& Ord, J.K. (1994). The past and the future of forecasting research. International Journal of Forecasting, 10, 151-159.

De Gooijer, J.G. (1990). Editorial: The role of time series analysis in forecasting: A personal view. International Journal of Forecasting, 6, 449-451.

De Gooijer, J.G., \& Gannoun, A. (2000). Nonparametric conditional predictive regions for time series. Computational Statistics \& Data Analysis, 33, 259-275.

Dekimpe, M.G., \& Hanssens, D.M. (2000). Time-series models in marketing: past, present and future. International Journal of Research in Marketing, 17, 183-193.

Durbin, J., \& Koopman, S.J. (2001). Time Series Analysis by State Space Methods, Oxford: Oxford University Press.

Engle, R.F \& Manganelli, S. (2004). CAViaR: Conditional autoregressive value at risk by regression quantiles. Journal of Business \& Economic Statistics, 22, 367-381.

Engle, R.F. \& Russell, J.R. (1998). Autoregressive conditional duration: a new model for irregularly spaced transactions data. Econometrica, 66, 1127-1162.

Forni, M., Hallin, M., Lippi, M., \& Reichlin, L. (2005). The generalized dynamic factor model: one-sided estimation and forecasting. Journal of the American Statistical Association, 100, 830-840.

Harvey, A.C. (1989). Forecasting, Structural Time Series Models and the Kalman Filter, Cambridge: Cambridge University Press.

Koenker, R.W., \& Bassett, G.W. (1978). Regression quantiles. Econometrica, 46, 33-50.

Ord, J.K. (1988). Future developments in forecasting: The time series connexion. International Journal of Forecasting, 4, 389-401.

Peña, D., \& Poncela, P. (2004). Forecasting with nonstationary dynamic factor models. Journal of Econometrics, 119, 291-321. 
Polonik, W., \& Yao, Q. (2000). Conditional minimum volume predictive regions for stochastic processes. Journal of the American Statistical Association, 95, 509-519.

Ramsay, J.O., \& Silverman, B.W. (1997). Functional Data Analysis, New York: Springer-Verlag. (2nd ed. 2005).

Stock, J.H., \& Watson, M.W. (1999). A comparison of linear and nonlinear models for forecasting macroeconomic time series. In R.F. Engle and H. White (eds.). Cointegration, Causality and Forecasting, pp. 1-44. Oxford: Oxford University Press.

Stock, J.H., \& Watson, M.W. (2002). Forecasting using principal components from a large number of predictors. Journal of the American Statistical Association, 97, 1167-1179.

Stock, J.H., \& Watson, M.W. (2004). Combination forecasts of output growth in a seven-country data set. Journal of Forecasting, 23, 405-430.

Tsay, R.S. (2000). Time series and forecasting: Brief history and future research. Journal of the American Statistical Association, 95, 638-643.

West, M., \& Harrison, P.J. (1989). Bayesian Forecasting and Dynamic Models, New York: Springer Verlag (2nd ed. 1997).

Yao, Q., \& Tong, H. (1995). On initial-condition and prediction in nonlinear stochastic systems. Bulletin International Statistical Institute, IP10.3, 395-412. 